\title{
Differential Release of $\beta$-Amyloid from Dendrite- Versus Axon-Targeted APP
}

\author{
Scott R. DeBoer, ${ }^{1,2}$ Georgia Dolios, ${ }^{4}$ Rong Wang, ${ }^{4}$ and Sangram S. Sisodia ${ }^{3}$ \\ ${ }^{1}$ Medical Scientist Training Program, ${ }^{2}$ Committee on Neurobiology, and ${ }^{3}$ Department of Neurobiology, The University of Chicago, Chicago, Illinois 60637, \\ and ${ }^{4}$ Department of Genetics and Genomic Sciences, Icahn School of Medicine at Mount Sinai, New York, New York 10029
}

The $\beta$-amyloid precursor protein (APP) plays a central role in the pathogenesis of Alzheimer's disease. APP is processed in neurons, but little is known about the relative contributions of presynaptic or postsynaptic compartments to the release of A $\beta$ peptides. To address this issue, we transduced primary neurons from Sprague-Dawley rats or APP ${ }^{-1-}$ mice (B6.129S7-App $\left.{ }^{\text {tm } 1 D b o} / \mathrm{J}\right)$ with lentiviral constructs expressing APP chimeras harboring targeting motifs from low-density lipoprotein receptor or neuron-glia cell-adhesion molecule to polarize expression to either dendritic or axonal membranes, respectively. Using imaging and quantitative biochemical approaches, we now report that APP selectively targeted to either axons or dendrites leads to the secretion of full-length A $\beta$ peptides with significantly elevated release from dendritic compartments. These findings reveal that the enzymatic machinery required for production of $A \beta$ peptides are operative both in presynaptic and postsynaptic compartments of primary neurons, leading to the suggestion that $\mathrm{A} \beta$ mediated impairments in glutamatergic neurotransmission is the result of $\mathrm{A} \beta$ release from both local and distal neuronal compartments.

Key words: $\beta$-amyloid; A $\beta$; amyloid precursor protein; APP; axonal targeting; dendritic targeting

\section{Introduction}

Alzheimer's disease (AD), the most prevalent cause of dementia, is pathologically characterized by the presence of extracellular deposits of $A \beta$ peptides in senile plaques. $A \beta$ is a complex set of peptides generated by the proteolytic processing of amyloid precursor protein (APP), which is encoded by a gene that is mutated or duplicated in several pedigrees with familial forms of Alzheimer's disease (Price and Sisodia, 1998). The processing of APP in non-neuronal cells has been extensively investigated (Haass et al., 2012), but information regarding the subcellular sites of $\mathrm{A} \beta$ production and release from neurons is limited. Synaptic activity increases $\mathrm{A} \beta$ release (Kamenetz et al., 2003; Cirrito et al., 2005), and high levels of $\mathrm{A} \beta$ inhibit the induction of long-term potentiation (Kamenetz et al., 2003). Indeed, in organotypic, hippocampal slice cultures, transient overexpression of APP via the Sindbis virus has revealed that $A \beta$ released from either axonal or dendritic compartments leads to reduced spine density in neighboring dendrites (Wei et al., 2010). In that setting, APP was expressed

Received June 3, 2014; revised July 22, 2014; accepted July 30, 2014.

Author contributions: S.R.D., R.W., and S.S.S. designed research; S.R.D. and G.D. performed research; S.R.D. contributed unpublished reagents/analytic tools; S.R.D., G.D., R.W., and S.S.S. analyzed data; S.R.D. and S.S.S. wrote the paper.

This work was supported by The Adler Foundation, Edward H. Levy Fund Cure Alzheimer's Fund (S.S.S.), NIH/ NINDS P30 NS061777 (R.W., G.D.), and NIA F30AG034001(S.R.D.). We thank Janice Wang and Dr Jeremy Marks, for technical advice on primary neuron cultures, and DrVytas Byndokas for assistance with microscopy. The corresponding author (S.S.S.) discloses that he is a paid consultant of Eisai Research Laboratories, AZ Therapies, and Jannsen Pharmaceutica NV, but is not a shareholder in any company that is a maker or owner of a FDA-regulated drug or device.

The authors declare no competing financial interests.

Correspondence should be addressed to Dr Sangram S. Sisodia, The University of Chicago, Department of Neurobiology, 947 East $58^{\text {th }}$ Street, AB 308, Chicago, IL 60637. E-mail: ssisodia@bsd.uchicago.edu.

DOI:10.1523/JNEUROSCI.2255-14.2014

Copyright $\odot 2014$ the authors $\quad 0270-6474 / 14 / 3412313-15 \$ 15.00 / 0$ in CA1 pyramidal neurons to assess the effects of postsynaptically released $\mathrm{A} \beta$ on the dendritic spines of noninfected CA1 cells or was expressed in CA3 projection neurons to assess the impact of presynaptically released $A \beta$ on the dendritic spines of CA1 neurons. Although of significant interest, the details regarding APP expression, APP processing, or the identity of $A \beta$ peptides released from presynaptic or postsynaptic compartments were not obtained. These uncertainties are virtually impossible to address in this experimental paradigm, and hence, we chose an alternative strategy in which primary hippocampal neuron cultures were transduced with lentiviruses that harbor APP chimeras that are selectively targeted to axonal or dendritic compartments. We then examined APP processing and released $\mathrm{A} \beta$ peptides using biochemical and mass spectrometric approaches. We now document that neither endogenous rodent APP nor exogenous human APP are processed by $\alpha$ - then $\gamma$-secretases to generate $\mathrm{p} 3$ (A $\beta 17-40)$, but rather are processed by $\beta$ - and $\gamma$-secretases to generate full-length $\mathrm{A} \beta$ and an array of $\mathrm{A} \beta$ peptide-related species. Moreover, the levels of $A \beta$ peptides released from dendrites are significantly elevated compared with the levels of $A \beta$ released from axonal compartments. These findings extend the observations by Wei et al. (2010) and establish that the enzymatic machinery responsible for the generation of $\mathrm{A} \beta$ peptides are operant in both presynaptic and postsynaptic compartments.

\section{Materials and Methods}

Antibodies and reagents. Exogenously expressed, myc-tagged human APP constructs were detected with monoclonal antibody (mAb) P2-1 (human-specific epitope in N-terminus of APP; Van Nostrand et al., 1989) or with rabbit anti-myc-1 affinity purified antibody (for immunofluorescence studies) or serum (for immunoprecipitation studies; a kind gift from Dr Philip Wong, Johns Hopkins University School of Medicine, Baltimore, MD). sAPP total was detected with $\mathrm{mAb} 22 \mathrm{C} 11$ specific for an 
N-terminal epitope of APP. sAPP $\alpha$ was immunoprecipitated from media using mAb 6E10. SAPP $\beta$ was detected with polyclonal antibody 192-WT from Elan. A $\beta$ was immunoprecipitated from media using monoclonal antibody 4G8 (anti $\mathrm{A} \beta_{17-24}$ ), 6E10 (human-specific anti-A $\left.\beta_{1-12}\right)$, or $2 \mathrm{G} 3$ (anti-A $\beta_{\mathrm{n}-40}$ ) and detected by Western blot with 26D6 (monoclonal anti$\left.\mathrm{A} \beta_{1-12}\right)$. Anti-rabbit IgG-800 nm secondary antibody was used with the LI-COR system for quantification of sAPP $\beta$.

DNA constructs. The APP695-WT-myc cDNA was previously generated in this lab by blunt-end ligation as previously described (Lo et al., 1994). Dr Guojun Bu, Mayo Clinic, kindly provided the human low-density lipoprotein receptor (LDLR) cDNA. The LDLR cytoplasmic tail was then amplified using PCR, and this tail was ligated to digested APP cDNA. Dr Bettina Winckler, University of Virginia, kindly provided cDNA containing the $\mathrm{C}$-terminus of the cytoplasmic tail of neuron-glia cell adhesion molecule (NgCAM). This tail was amplified using PCR and ligested to digested APP cDNA to create APP-NgCAM $\triangle$ YRSL. The remainder of the NgCAM cytoplasmic tail was created using synthetic oligos (5'GCGCGCCTTAAGA AGAAACAGAAACGCAGCAAGGGGGGCAA GTATTCGGTGAAGGACAAGGAGGACACG CAGGTGGACTCTGAGGCGCGGCCCATGA AGGATGAGACCTTTGGGGAGTACAGGTC GTTGGAGAGCGAAGCGGAGAAGGGTTCG GCTTCGGGTTC3' and5' GCGCGCGTCGAC CCGCGGTACTGCCCGATGAAGGATCCAT CCTCATTGAACTGCACATCCCCGCTGCC TCCGTACCCCGCCAGGCTGTCTTCGCTG CCCGCCGCGCACGGACCCCGACCCGGAG AACCCACACCGGAACCGGCACCGGAACC CGAAGCCGAACCCTTCTC- $3^{\prime}$ ), then amplified, digested, and ligated to digested APP-NgCAM $\triangle$ YRSL cDNA to create the APPNgCAM construct with the sequence shown in Figure $5 B$. Likewise, the APP $\Delta$ Cterm construct was created using PCR. pCI GFP-APP-myc cDNA containing M596V/K612V mutations were kindly provided by Dr Roberto Malinow, University of California San Diego. The region of the cDNA containing the mutations were removed by digest with SacI and Xbal and subcloned into the APP constructs also digested with Sacl and Xba1. All constructs include a myc tag at the $\mathrm{COOH}$-terminus consisting of the sequence MEQKLISEEDLN. Assembled APP constructs were verified by sequencing and subcloned into the $\mathrm{pCDH} 1$ lentiviral backbone for lentiviral production (System Biosciences).

Cell culture. Primary hippocampal neuron cultures were prepared as previously described (Kaech and Banker, 2006). Briefly, hippocampi were dissected from E18 rat pups of either sex (Sprague-Dawley) or E17 APP ${ }^{-1-}$ mice of either sex (B6.129S7Apptm1Dbo/J; Zheng et al., 1995), and then dissociated and grown on poly-lysine-coated glass coverslips for immunofluorescence or on polylysine-coated plastic for biochemistry using neurobasal medium with B27 supplement and GlutaMAX (Invitrogen).

Lentiviral transductions. The pCDH1 CMV MCS1 EF1 copepod GFP (copGFP) lentiviral backbone (System Biosciences) was modified. For APP expression, the CMV MCS1 EF1 copGFP region was removed by digestion with SpeI and SalI followed by blunt end creation with Klenow dendrites.
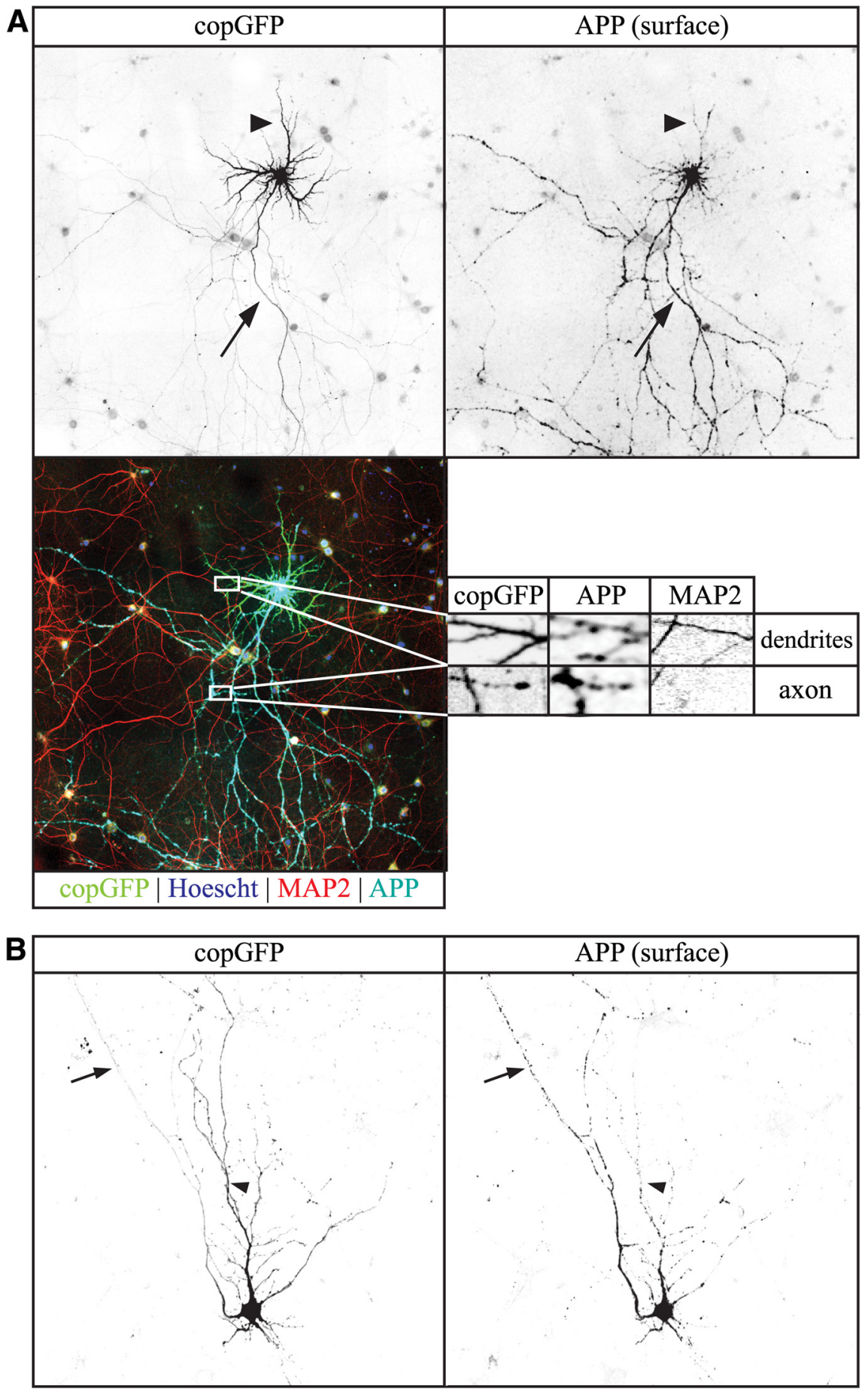

Figure 1. APP staining in primary neurons. Neurons at 15 DIV cotransfected $24 \mathrm{~h}$ earlier with plasmids encoding copGFP and APP. copGFP is present throughout the entire neuron, and APP is found at the cell surface $(\boldsymbol{A})$ and intracellularly $(\boldsymbol{B})$ in both axons and dendrites. $\boldsymbol{A}$, Inset, APP costaining in MAP2-positive dendrites and MAP2-negative axons. Arrows, axons; arrowheads, polymerase to create pCDH1 "empty". The CAG compound promoter with APP was then subcloned into the pCDH1 "empty" vector in one step into the SalI site. Correct orientation was determined by restriction enzyme digest and sequencing. The CAG promoter was subcloned out of the pCLNCXv2 CAG GFP plasmid. pCDH1 CAG APP-chimeras were cotransfected into the HEK293 TN packaging cell line with the packaging plasmids and 1:100 pCDH1 CMV MCS1 EF1 copGFP for titer determination (APP:copGFP). The media containing pseudotyped lentiviral particles were collected at 24 and $48 \mathrm{~h}$ post-transfection, and then pooled. 

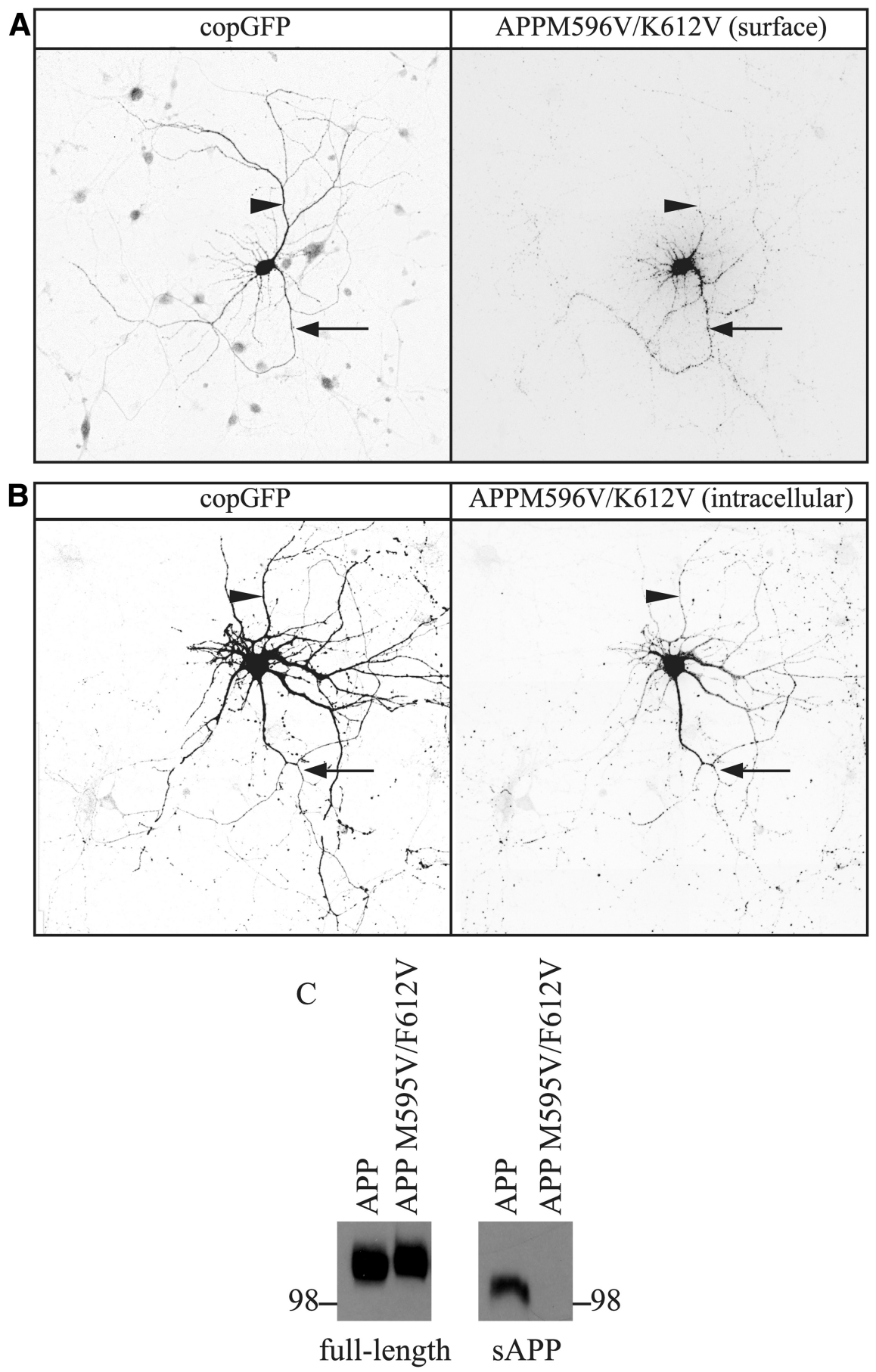

Figure 2. APP-M596V/K612V staining in primary neurons. Neurons at $15 \mathrm{DIV}$ cotransfected $24 \mathrm{~h}$ earlier with plasmids encoding copGFP and APP-M596V/K612V. When expressed in primary neurons, APP M596V/K612V is found the cell surface $(A)$ and intracellularly $(\boldsymbol{B})$ in both axons and dendrites. APP and APP M596V/K612V expression in HEK293 cells $(\boldsymbol{C})$ shows greatly reduced APP ectodomain shedding when the $\alpha$ - and $\beta$-secretase sites are mutated (left, lystate; right, conditioned medium). Arrows, axons; arrowheads, dendrites.

The particles were subsequently precipitated with PEG-IT (System Biosciences), resuspended, and stored at -80 . At $7 \mathrm{~d}$ in vitro (DIV), neurons were transduced with lentiviral particles for $6 \mathrm{~h}$ at $37^{\circ} \mathrm{C}$ in the presence of $5 \mu \mathrm{g} / \mathrm{ml}$ polybrene at an multiplicity of infection (MOI) $\geq 5$. Neurons were transduced at $90 \%$ efficiency for biochemistry experiments.

Immunocytochemistry and quantification. Primary neuron cultures were cotransfected at 14 DIV with pCDH1 CAG APP constructs and pCDH1 EF1 copGFP. At 15-16 DIV, 24-48 h post-transfection, cells were labeled live at room temperature with P2-1, rinsed, then fixed in $4 \%$ paraformaldehyde and $4 \%$ sucrose in PBS at $\mathrm{pH}$ 7.3. Cells were then blocked in 5\% BSA in PBS. Anti-mouse IgG Cy5-conjugated secondary was used against P2-1. For intracellular staining, cells were fixed then permeabilized in PBS $+0.25 \%$ Triton $\mathrm{X}-100$ for $5 \mathrm{~min}$ at $4^{\circ} \mathrm{C}$, followed by staining with either rabbit antiMAP2 (Sigma-Aldrich) or rabbit anti-myc1 and anti-rabbit IgG Cy3-conjugated secondary. Hoechst was included for nuclear staining.

Soluble copGFP expression was used to visualize the entire neuron and identify the axons and dendrites by morphology as previously described (Das and Banker, 2006). Axons are thin and travel long distances, often crossing back over themselves, whereas dendrites start thick and taper down over a relatively short distance with visible dendritic spines. Costaining with MAP2 verified correct identification of dendrites. Cells were imaged with a $20 \times$ objective on the Marianas microscope, tiling $5 \times 5$ fields-of-view $\sim 2 \mathrm{~mm}^{2}$ of total area. Tiling was accomplished using the ImageJ (Fiji) stitching plug-in. Raw images were processed to correct for uneven illumination with a flat-field image, and the mean background was subtracted (calculated in neighboring nontransfected neurons). Neurons were picked at random, and all imaged neurons were included in the analysis as long as the axons and dendrites could be clearly distinguished. The entire axonal and dendritic arbors were traced using the ImageJ (Fiji) simple neurite tracing plug-in using the copGFP image. To calculate the axon-dendrite ratio, the mean pixel intensity along the dendrites and at least the proximal $1000 \mu \mathrm{m}$ of axon were measured. Therefore, a ratio of axon intensity per micrometer to dendrite intensity per micrometer was calculated for each individual neuron and, subsequently, for each construct, as previously described (Silverman et al., 2005; Das and Banker, 2006). To calculate the fraction of axonal staining versus dendritic staining, the extent of the dendritic arbors and axonal arbors was traced using the ImageJ neurite tracing macro. These 1-pixel-wide tracings were dilated to fit the diameters of the axon and dendrites. All APP staining within these tracings was then summed. The axonal fraction was calculated as (sum of axonal APP signal intensity/sum of dendritic APP signal intensity + sum of axonal APP signal intensity). The dendritic fraction was calculated as (sum of dendritic APP signal intensity/sum of dendritic APP signal intensity + sum of axonal APP signal intensity), as shown by Jareb and Banker (1998).

Conditioned media preparation and metabolic labeling. For biochemical analysis of APP metabolic fragments, neurons were transduced at high MOI at 7 DIV, as described above. At 13-14 DIV, half of the media was exchanged for fresh neuronal maintenance media. Then, $48 \mathrm{~h}$ later, at 15-16 DIV, the media was collected, and phenylmethanesulfonylfluoride (PMSF) was added to $1 \mathrm{~mm}$. Cellular debris was pelleted at maximum speed on a tabletop centrifuge, and then the supernatant stored at $-80^{\circ} \mathrm{C}$ until use. For Western blot analysis, neurons were rinsed with $\mathrm{PBS}$ then lysed in $1 \times$ immunoprecipitation (IP) buffer (150 mм NaCl, 10 mм Tris-HCl, pH 7.6, 1 mм EDTA, 0.5\% NP-40, $0.5 \%$ sodium deoxycholate $+1 \times$ protease inhibitor cocktail; 
A

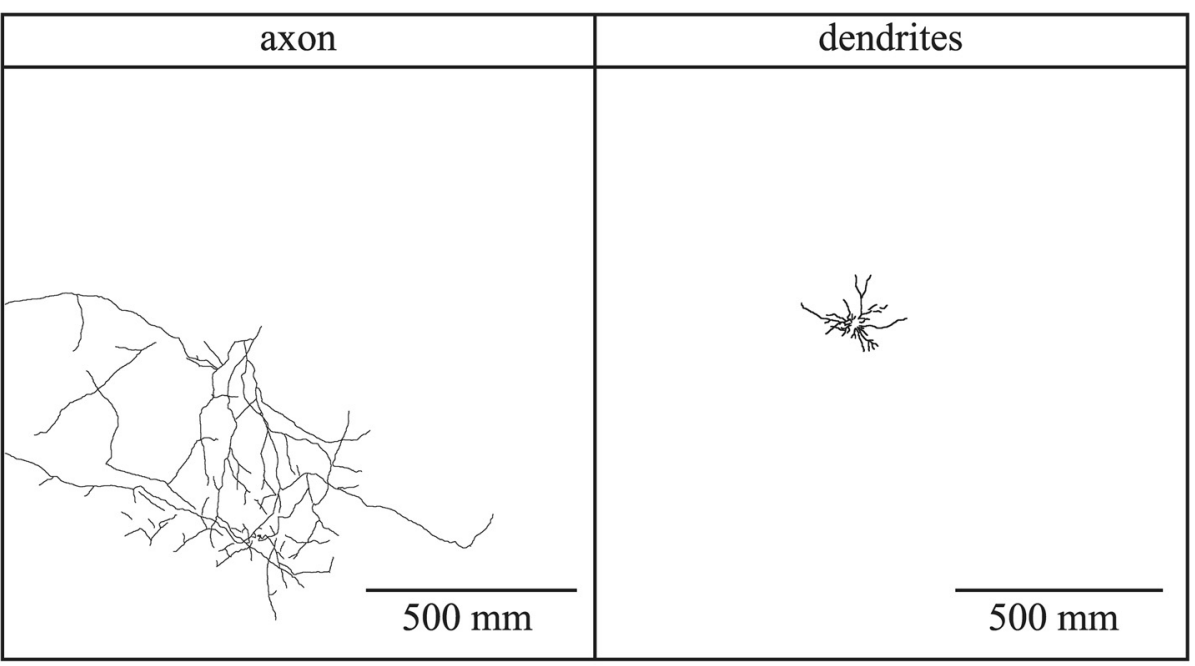

B

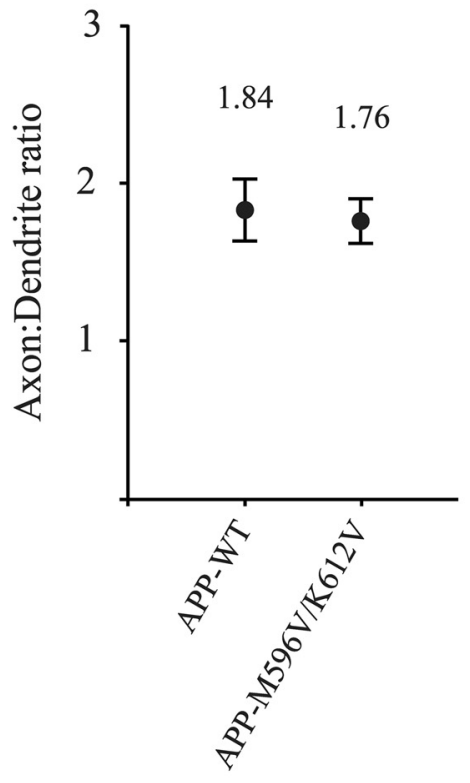

C

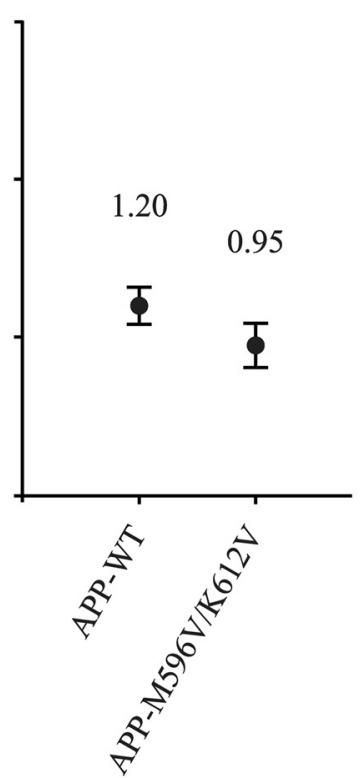

D

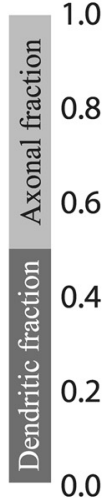

$\mathbf{E}$

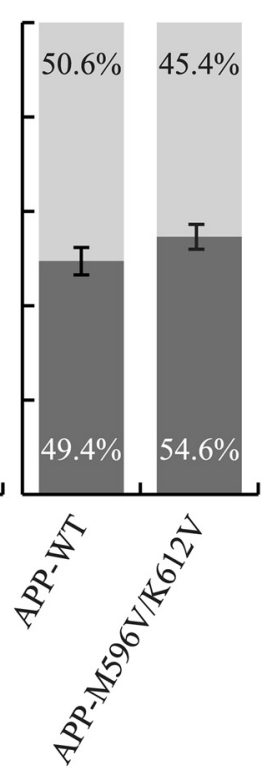

Figure 3. Quantification of protein polarity. $A$, To quantify protein levels in the processes, the axonal and dendritic arbors were traced, and then these tracings were used to measure APP staining. The example in $\boldsymbol{A}$ is a tracing of the neuron from Figure $1 A . \boldsymbol{B}, \boldsymbol{C}$, Ratios of APP staining in axons versus dendrites, as described in text. At the cell surface, both APP (B) and APP-M596V/K612V are found at higher levels in axon then dendrites, but intracellular levels are less polarized (C).D,E, The fraction of total APP staining is shown in axonal versus dendritic fractions. At the cell surface (D), the majority of APP protein is axonal, but intracellular levels $(\boldsymbol{E})$ are equally split between axons and dendrites.

Sigma-Aldrich) on ice. Cellular debris was pelleted at maximum speed on a tabletop centrifuge, and then the supernatant was stored at $-80^{\circ} \mathrm{C}$ until use. For metabolic labeling, neurons were starved for $15 \mathrm{~min}$ at $37^{\circ} \mathrm{C}$ in DMEM, without methionine, diluted with water to equal the osmolarity of neurobasal medium, plus $1 \times$ B27 supplement and GlutaMAX. Neurons were then labeled with a $10 \mathrm{~min}$ pulse of ${ }^{35} \mathrm{~S}$-methionine to determine synthetic rates or with a $4 \mathrm{~h}$ continuous pulse for steady-state levels. After labeling, neurons were rinsed with PBS then lysed with $1 \times$ IP buffer (see above) on ice. The $4 \mathrm{~h}$ media was collected with $1 \mathrm{~mm}$ PMSF, cellular debris pelleted, then supernatant stored at $-80^{\circ} \mathrm{C}$. To determine the ${ }^{35} \mathrm{~S}$-methionine incorporation rate, an aliquot of the labeled lysates was pelleted in the presence of $1 \%$ BSA in PBS with trichloroacetic acid (TCA) on ice. The TCA pelleted samples were then assayed using scintillation liquid to determine the counts per minute per microliter of lysate. Equal counts were used for immunoprecipitation from lysates, and the immunoprecipitates from media were adjusted based on counts of the $4 \mathrm{~h}$ lysate. Full-length APP and APP-CTFs were immunoprecipitated using anti-mycl serum. $A \beta$ was precipitated using $4 \mathrm{G} 8$ (anti-A $\left.\beta_{17-24}\right)$ or 6E10 (anti-human $A \beta_{1-10}$ ). Immunoprecipitates were fractionated on $16.5 \%$ tris-tricine gels and then transferred to PVDF membranes. The PVDF membranes were exposed to phosphorimaging screens, and then the screens were scanned to quantify the counts from labeled APP or APP metabolites. $A \beta$ levels were normalized to the synthetic rates of fulllength APP at 10 min. $A \beta$ from each construct was then quantified in relation to $\mathrm{A} \beta$ from $\mathrm{APP}-\mathrm{WT}$.

MALDI-TOF mass spectrometry. Conditioned media were prepared as described above. $A \beta 17-40$ (p3) was generated by digesting 10 or 100 nmol of commercially available $\mathrm{A} \beta 1-40$ with $22 \mathrm{ng}$ of trypsin for $30 \mathrm{~min}$ at $37^{\circ} \mathrm{C}$. $\mathrm{A} \beta$ peptides were immunoprecipitated using monoclonal antibody $4 \mathrm{G} 8$ or $2 \mathrm{G} 3$ incubated overnight at $4^{\circ} \mathrm{C}$ with protein $\mathrm{A} / \mathrm{G}$ beads. The following day, after removing the supernatant, the beads were washed two times with dilution buffer $(150 \mathrm{~mm} \mathrm{NaCl}, 0.1 \%$ n-octyl glucoside, 10 $\mathrm{mm}$ Tris-HCl), next two times with $10 \mathrm{~mm}$ Tris- $\mathrm{HCl}$, and finally with water. $\mathrm{A} \beta$ peptides were extracted with $3 \mu \mathrm{l}$ of formic acid/water/isopro- 
A

Human

DAEFRHDSGYEVHHQKLVFFAEDVGSNKGAI IGLMVGGVVIA * * * Rodent DAEFGHDSGFEVRHQKLVFFAEDVGSNKGAI IGLMVGGVVIA

B

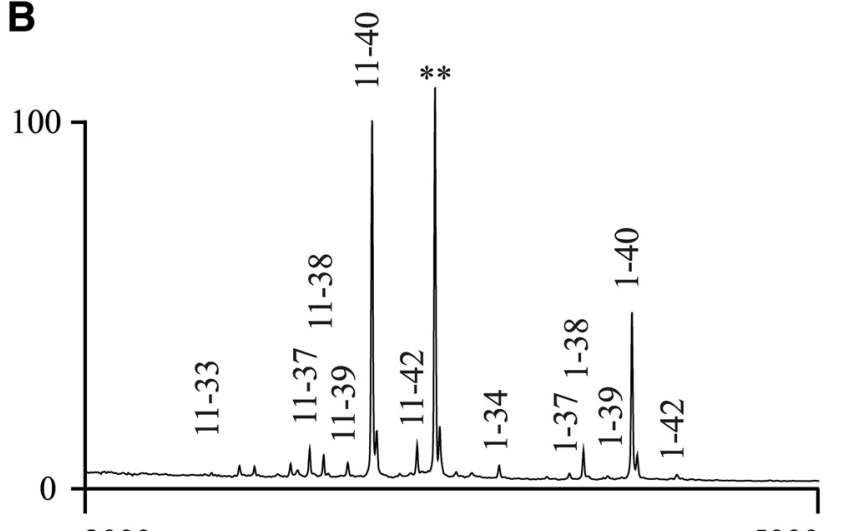

C
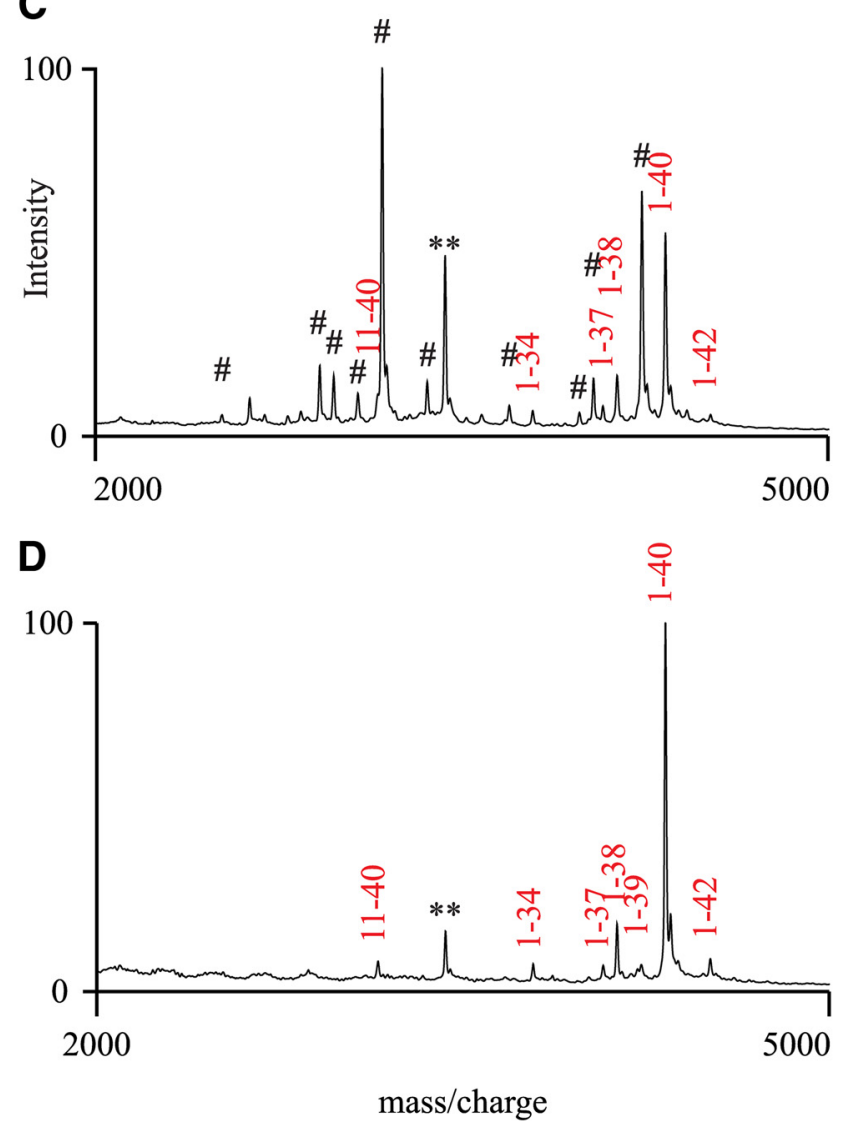

Figure 4. Soluble $A \beta$ peptides derived from APP processing in neurons. $A$, The alignment of rodent and human $A \beta$ sequences shows 3 aa differences, which allow for distinction between exogenously and endogenously derived $A \beta$ by mass. $\boldsymbol{B}$, Endogenous APP produces a number of $1-n$ and $11-n A \beta$ species, with $11-40$ being the predominant peptide. In rat neurons $(C)$ and $\mathrm{APP}^{-1-}$ mouse neurons $(\boldsymbol{D})$, human APP also produces a number of $1-n \mathrm{~A} \beta$ species, but only a small amount of 11-40; **unidentified peak; \#rodent $A \beta$ species.

panol (1:4:4, v/v/v), containing saturated $\alpha$-cyano-4-hydroxycinnamic acid (UV-laser desorption matrix) and $200 \mathrm{~nm}$ bovine insulin (internal mass calibrant). The extraction solution $(1.5 \mu \mathrm{l})$ was loaded onto the mass spectrometer sample probe and dried at ambient temperature. Mass spectra were measured using an UV-laser desorption/ionization time-of-flight mass spectrometer (AB SCIEX TOF/TOF 5800) at Mt Sinai Medical Center, Miami Beach, FL. Spectra were identified as A $\beta$ peaks based on the predicted molecular weight of human or rodent $A \beta$ species. An identified $A \beta$ species peak must contain the $4 \mathrm{G} 8$ or $2 \mathrm{G} 3$ epitope to be considered valid.

Statistical analysis. Mean values were compared with each other using an unpaired $t$ test, unequal variance. Values were considered significantly different from each other if $p<0.05$.

\section{Results \\ Polarized distribution of APP in primary hippocampal neuron cultures}

To examine the distribution of APP in primary hippocampal neurons, we transfected rat primary hippocampal neurons at 14 DIV with constructs that express a c-myc-tagged human APP695 and copGFP, a soluble fluorescent protein that fills the entire neuron and allows for direct visualization of the processes. At 15-16 DIV, the neurons are well differentiated, and axons and dendrites can be distinguished from each other based on morphologic criteria, as previously described (Das and Banker, 2006). Moreover, we validated dendritic identity by indirect immunofluorescence (IF) microscopy using anti-MAP2 antibodies (Fig. 1A). To determine the steady-state levels of human APP-695 on the cell surface at 15-16 DIV, live cells were incubated at room temperature for 5 min with the human APP-specific mAb P2-1 antibody that recognizes a sulfhydryl-dependent conformational epitope in the APP ectodomain (Van Nostrand et al., 1989), and then fixed. Visualization of bound P2-1 using a fluorescently labeled secondary antibody revealed that human APP is found on both axonal and dendritic surfaces (Fig. 1A). Using the copGFP signal as a guide, 1-pixel-wide lines were traced along the center of all dendrites and at least the proximal $1000 \mu \mathrm{m}$ of the axon (see Fig. 3A). After a shading correction and subtraction of background, the signal intensity of APP staining was quantified and averaged along those dendritic and axonal tracings to obtain the average axonal APP signal per micrometer and average dendritic APP signal per micrometer for each neuron. An axon-dendrite ratio was then generated (axonal APP signal per micrometer: dendritic APP signal per micrometer), as previously described (Das and Banker, 2006). These studies revealed that human APP is preferentially polarized to the axonal surface, with an axondendrite ratio of $1.84 \pm 0.28$ (see Fig. $3 B$ ). Therefore, there is $1.84 \times$ more APP signal intensity per micrometer on average on the axonal surface relative to the dendritic surface. In parallel, we fixed, and then permeabilized, neurons transfected with constructs expressing myc-tagged human APP-695 and copGFP and performed IF studies using myc-1 antibodies. In this case, we observed that human APP-695 is distributed throughout axons and dendrites with an axon-dendrite ratio of $1.20 \pm 0.12$ (see Fig. 3C).

We also quantified the polarization in a second manner, comparing the percentage of total APP staining found in axons versus total APP staining in dendrites, as previously described byin Jareb and Banker (1998). Briefly, we traced all APP containing axons and dendrites of each neuron using copGFP and MAP2 staining as guides, and total APP staining signal intensity was summed for each neuron separately in both axons and dendrites. The percentage of total-surface staining of APP on axonal membranes versus on dendritic membranes is defined as the sum of APP signal (P2-1) on the axonal membranes divided by the sum of APP on axonal membranes plus APP on dendritic membranes $\times 100$, and the percentage of APP on dendritic surfaces is defined as the sum of APP on dendritic surfaces divided by the sum of APP on axonal and dendritic surfaces $\times 100$. For intracellular APP, the 
Table 1. Soluble $A \boldsymbol{\beta}$ species derived from APP processing in neurons

\begin{tabular}{|c|c|c|c|c|}
\hline Species & $A \beta$ species & Sequence & $M_{r}$ (observed) & $M_{r}$ (calculated) \\
\hline \multirow[t]{7}{*}{ Human } & $1-42$ & DAEFRHDSG YEVHHQKLVF FAEDVGSNKG AIIGLMVGGV VIA & 4514.67 & 4514.10 \\
\hline & $1-40$ & DAEFRHDSG YEVHHQKLVF FAEDVGSNKG AIIGLMVGGVV V & 4330.87 & 4329.86 \\
\hline & $1-38$ & DAEFRHDSG YEVHHQKLVF FAEDVGSNKG AIIGLMVGG & 4132.46 & 4131.59 \\
\hline & $1-37$ & DAEFRHDSG YEVHHQKLVF FAEDVGSNKG AIIGLMVG & 4075.75 & 4074.54 \\
\hline & $1-34$ & DAEFRHDSG YEVHHQKLVF FAEDVGSNKG AIIGL & 3788.64 & 3787.16 \\
\hline & $11-40$ & EVHHQKLVF FAEDVGSNKG AIIGLMVGGV V & 3152.58 & 3151.67 \\
\hline & $17-40^{*}$ & LVFFAEDVGSNKG AIIGLMVGGVV & 2393.46 & 2392.84 \\
\hline \multirow[t]{13}{*}{ Rodent } & $1-42$ & DAEFGHDSG FEVRHQKLVF FAEDVGSNKG AIIGLMVGGVVIA & 4419.10 & 4418.01 \\
\hline & $1-40$ & DAEFGHDSG FEVRHQKLVF FAEDVGSNKG AIIGLMVGGVV & 4235.30 & 4233.77 \\
\hline & $1-39$ & DAEFGHDSG FEVRHQKLVF FAEDVGSNKG AIIGLMVGGV & 4136.33 & 4134.64 \\
\hline & $1-38$ & DAEFGHDSG FEVRHQKLVF FAEDVGSNKG AIIGLMVGG & 4036.94 & 4035.50 \\
\hline & $1-37$ & DAEFGHDSG FEVRHQKLVF FAEDVGSNKG AIIGLMVG & 3979.92 & 3978.45 \\
\hline & $1-34$ & DAEFGHDSG FEVRHQKLVF FAEDVGSNKG AIIGL & 3692.32 & 3691.07 \\
\hline & $11-42$ & EVRHQKLVF FAEDVGSNKG AIIGLMVGGV VIA & 3356.91 & 3354.96 \\
\hline & $11-40$ & EVRHQKLVF FAEDVGSNKG AIIGLMVGGV V & 3172.76 & 3170.72 \\
\hline & $11-39$ & EVRHQKLVF FAEDVGSNKG AIIGLMVGGV & 3073.44 & 3071.59 \\
\hline & $11-38$ & EVRHQKLVF FAEDVGSNKG AIIGLMVGG & 2974.62 & 2972.46 \\
\hline & $11-37$ & EVRHQKLVF FAEDVGSNKG AIIGLMVG & 2917.41 & 2915.40 \\
\hline & $11-33$ & EVRHQKLVF FAEDVGSNKG AIIG & 2516.51 & 2514.87 \\
\hline & $17-40^{*}$ & LVF FAEDVGSNKG AIIGLMVGGV V & 2393.46 & 2392.84 \\
\hline
\end{tabular}

*17-40 only seen in trace amounts in high APP-expressing cultures (not shown).

A

APP

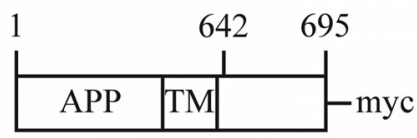

APP-LDLR

APP-NgCAM

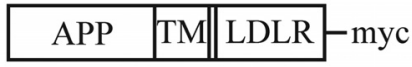

APP $\Delta$ Cterm

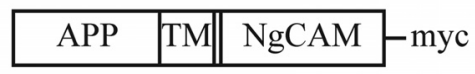

B

\section{COOH-terminus sequence}

\section{APP \\ KKKOYTSIHHGVVEVDAAVTPEERHLSK MQQNGYENPTYKFFEQMQNMEQKLISEEDLN}

\section{APP-LDLR}

KKKQKNWRLNINS INFDNPVYQKTTEDEVHI CHNQDGYSYPSRQMVSLEDDVAMEQKLISEE DLN

APP-NgCAM KKKQKRSKGGKYSVKDKEDTQVDSEARPMKD ETFGEYRSLESEAEKGSASGSGAGSGVGSPG RGPCAAGSEDSLAGYGGSGDVQFNEDGSFIG QYRGPGAGPGSSGPASPCAGPPLDMEQKLIS EEDLN

\section{APP $\Delta$ cterm}

KKKQMEQKLISEEDLN

Figure 5. Construction of the polarized APP constructs. $A$, Schematic representation of the different APP chimeric constructs used in this study. The APP cytoplasmic domain was replaced with the entire LDLR (APP-LDLR) or NgCAM (APP-NgCAM) cytoplasmic domains, or was deleted completely (APP $\Delta$ Cterm). All constructs contain a myc-tag at the very $\mathrm{COOH}$-terminus. $\boldsymbol{B}$, Complete cytoplasmic tail sequences of the different APP constructs. "KKKQ" are the four APP amino acids immediately following the transmembrane domain. Underlined sequences show the LDLR or NgCAM cytoplasmic domains. The myc-tag sequence is MEQKLISEEDLN.

neurons were fixed, permeabilized, and then stained with the polyclonal anti-mycl antibody, targeted against the myc-tag on the $\mathrm{COOH}$-terminus of the APP construct. The percentage of total-intracellular staining of APP in axons versus in dendrites is defined as the sum of APP signal in permeabilized axons divided by the sum of APP in permeabilized axons plus APP in permeabilized dendrites $\times 100$. Therefore, for surface APP, we calculated that total-surface staining of APP is $66.0 \pm 4.0 \%$ on the axonal membrane versus $44 \%$ on the dendritic membranes (see Fig. 3D). For intracellular APP, total-intracellular staining of APP is $50.6 \pm 5.8 \%$ in the axons versus $49.4 \%$ in the dendrites (see Fig. 3E).

Although these latter studies reveal a preferential steady-state cell surface distribution of human APP-695 to axonal plasma membranes, it was conceivable that our results may be confounded by the fact that APP is subject to constitutive processing by both $\alpha$ - and $\beta$-secretase (BACE 1 ) that leads to shedding of the ectodomain on the plasma membrane (Sisodia, 1992) and endosomal compartments (Koo and Squazzo, 1994; Kinoshita et al., 2003), respectively (for review, see Haass et al., 2012). To address this important issue, we generated constructs that express human APP-695 harboring mutations in the ectodomain that preclude processing by $\alpha$ - (K612V; Sisodia, 1992) or $\beta$ - secretases (M596V; Citron et al., 1992), and analyzed the polarity of the expressed protein in transduced hippocampal neurons.

We demonstrate that in transfected HEK293 cells, APP-695 M596V/K612V is not subject to ectodomain shedding, thus verifying that the mutations effectively blocked processing by $\alpha$ - and $\beta$-secretases (Fig. 2C). In transfected neurons, we show that the APP-695 M596V/K612V variant is present on both axonal and dendritic membranes (Fig. 2A) and in intracellular compartments (Fig. 2B). This APP-695 variant exhibits an axon-dendrite ratio of $1.76 \pm 0.17$ in nonpermeabilized cells and $0.95 \pm 0.17$ in permeabilized cells (Fig. $3 B, C$, respectively). At the surface, totalsurface staining of APP- $695 \mathrm{M} 596 \mathrm{~V} / \mathrm{K} 612 \mathrm{~V}$ is $63.9 \pm 4.0 \%$ on the axonal membranes versus $36.9 \%$ on the dendritic membranes (Fig. 3D). In permeabilized neurons, total-intracellular staining of APP-695 M596V/K612V is $45.4 \pm 5.3 \%$ in the axons versus $54.6 \%$ in the dendrites (Fig. 3E). These values are comparable to that observed for wild-type human APP-695 that harbors native $\alpha$ - and $\beta$-secretase cleavage sites.

Hence, we would argue that the polarization ratio of native human APP-695 on axonal versus dendritic membranes accurately reflects the distribution of full-length molecules and is not 


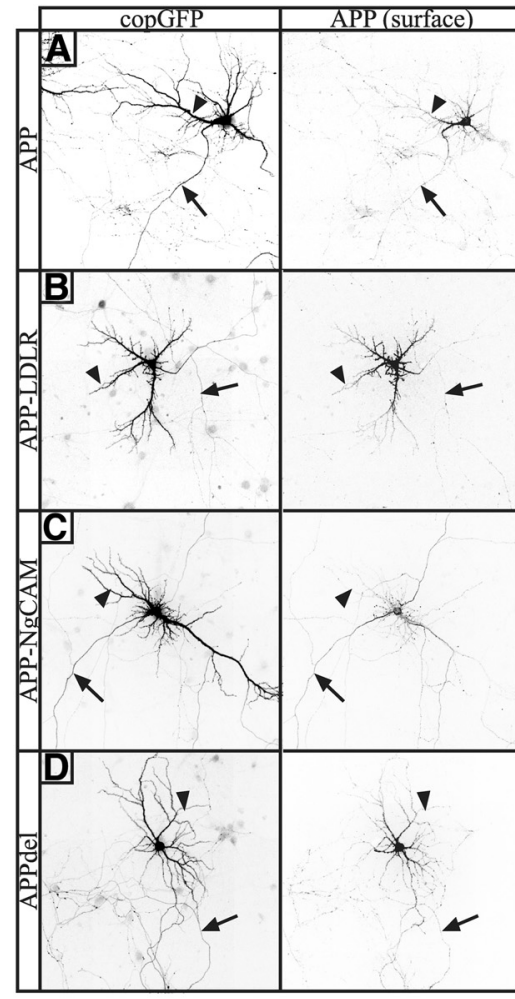

M
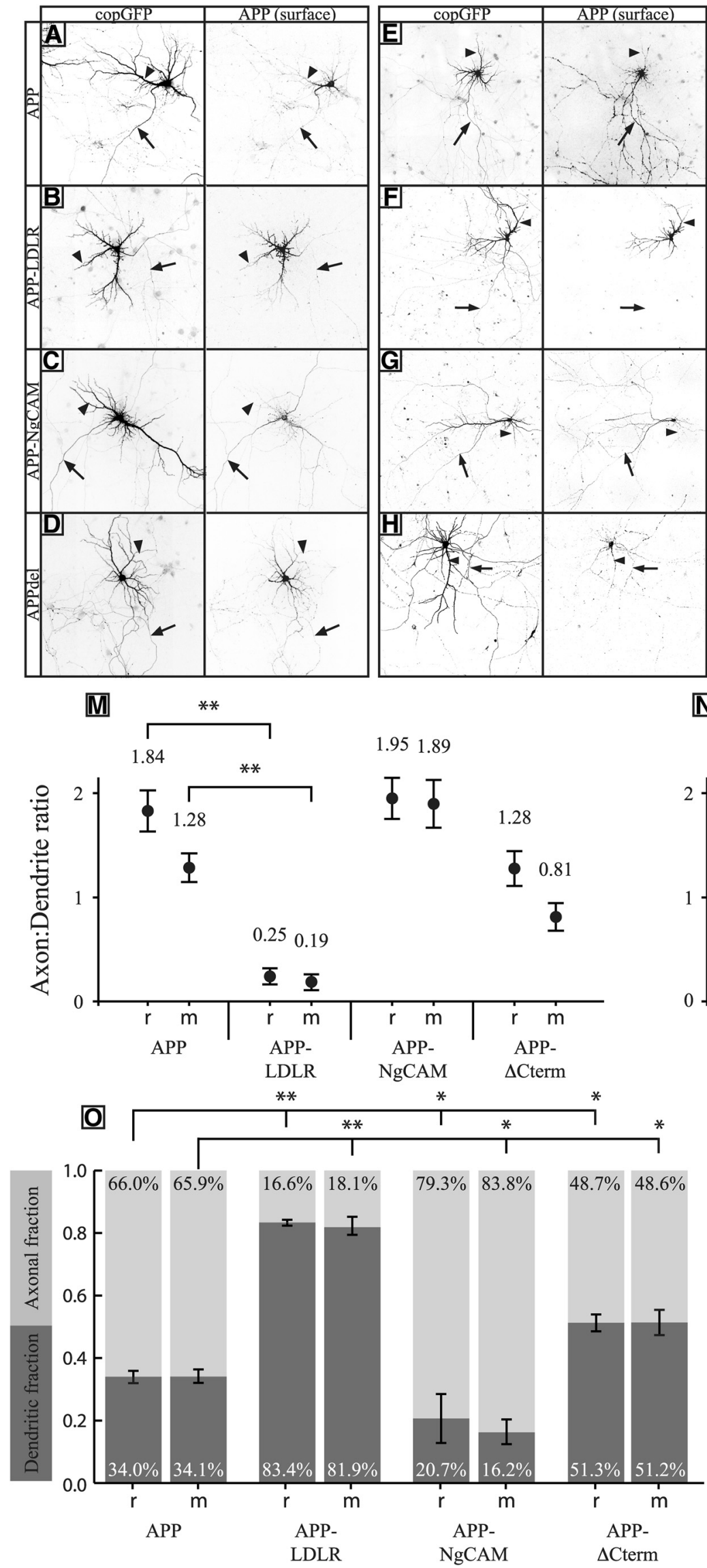

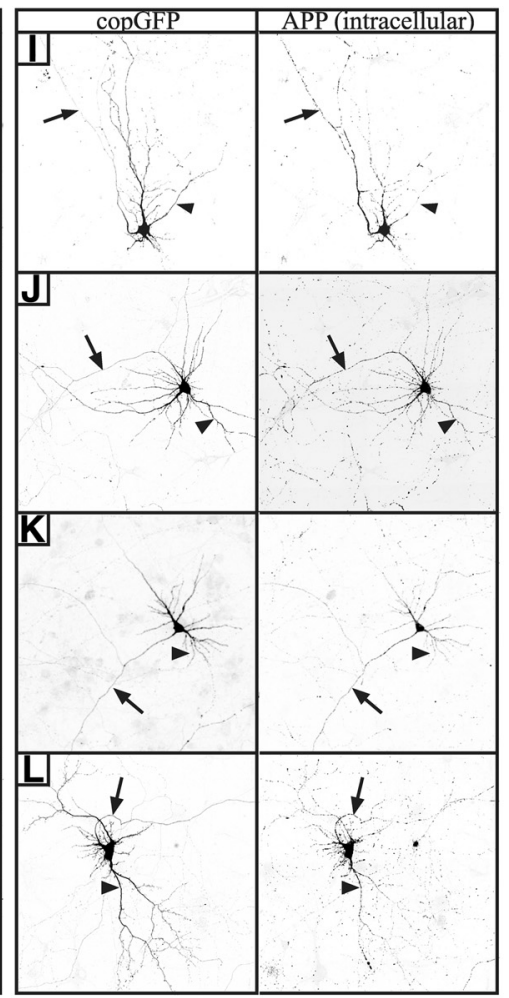

N

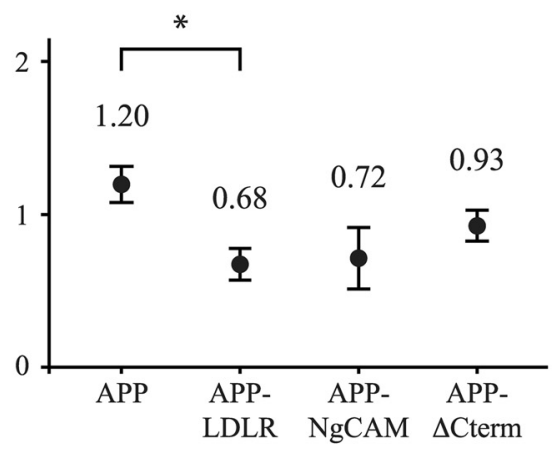

P

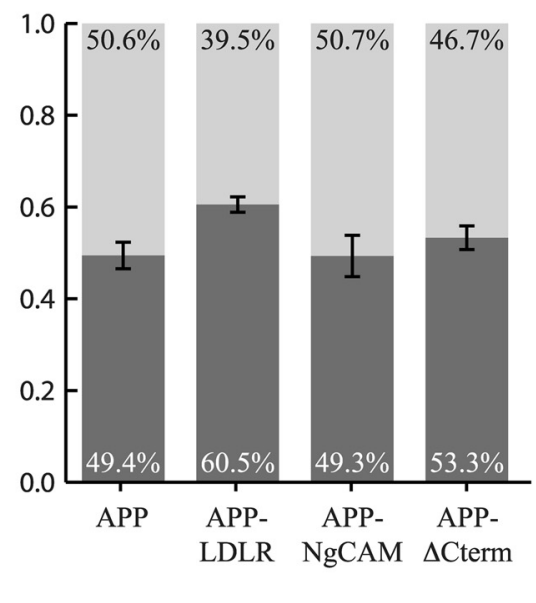


confounded by differences in ectodomain shedding activities in those plasma membrane compartments.

\section{$\mathrm{A} \boldsymbol{\beta}$ detected in neuronal conditioned media}

We collected the conditioned medium (CM) from 15 to 16 DIV primary rat hippocampal neuronal cultures transduced with lentivirus expressing human APP-695 to examine the profile of secreted $\mathrm{A} \beta$ species. The $\mathrm{CM}$ was subject to IP with $\mathrm{mAb} 4 \mathrm{G} 8$ that recognizes an epitope between $A \beta$ residues 17-24, a sequence that is conserved between rodent and human $\mathrm{A} \beta$ (Fig. $4 A$ ), and recovered immunoprecipitates were analyzed by matrix-assisted laser desorption/ionization (MALDI)-time-of-flight (TOF) mass spectrometry. In naive rat hippocampal neurons, we observed multiple $1-n$ and $11-n \mathrm{~A} \beta$ fragments, with 11-40 being the predominant peak (Fig. 4B). As A $\beta$ derived from human APP-695 differs from rodent $A \beta$ peptide at three positions (Fig. $4 A$ ), we could distinguish human and mouse $A \beta$-related species by IPMALDI-TOF. We detected human A $\beta 1-40$ in the CM of neurons expressing human APP-695, but very little human 11-40 (Fig. 4C). This finding is consistent with reports showing that rodent BACE is inefficient at cleaving at the +11 site in human APP (Cai et al., 2001). To confirm these findings, we transduced hippocampal neurons from APP-deficient mice $\left(\mathrm{APP}^{-/-}\right)$with lentivirus harboring human APP-695 and, again, we observe that the principal $\mathrm{A} \beta$-related peptide secreted into the $\mathrm{CM}$ is $1-40$ (Fig. 4D). Interestingly, in contrast to non-neuronal cells, wherein APP is processed by $\alpha$ - and $\gamma$-secretases to generate A $\beta 17-40$ peptides (expected molecular weight $\sim 2393$; Haass et al., 1993), we failed to observe these $A \beta$-related species in the CM of primary rat hippocampal neurons, rat hippocampal neurons expressing human APP-695, or human APP-695 expressed in $A P P^{-/-}$neurons (Fig. 4B-D, respectively). These studies raise the possibility that $\alpha$-secretase processing of rodent and human APP in primary rodent hippocampal neurons is inefficient, as has been previously described in neuronally differentiated P19 cells (Hung et al., 1992) and in primary cortical neuron cultures (Cai et al.,

\section{$\leftarrow$}

Figure 6. Distribution of the APP chimeras in neurons. Mouse APP ${ }^{-/-}$neurons (15-16 DIV; $\boldsymbol{A}-\boldsymbol{D})$ or rat neurons $(\boldsymbol{E}-\boldsymbol{L})$ cotransfected $24 \mathrm{~h}$ earlier with plasmids encoding copGFP and APP, APP-LDLR, APP-NgCAM, or APP $\Delta$ Cterm. Surface staining for APP in mouse APP ${ }^{-1-}(A)$ or rat neurons ( $\boldsymbol{E}$, as shown in Fig. 1) shows APP at the surface in both the axon (arrow) and dendrites (arrowhead). Surface staining for APP shows APP-LDLR (B, mouse APP ${ }^{-1-} ; \boldsymbol{F}$, rat) is highly polarized to the dendrites (arrowhead), with little axonal staining (arrow). APP-NgCAM ( $\boldsymbol{C}$, mouse $\mathrm{APP}^{-I-} ; G$, rat) is found at the axonal cell surface (arrow), with less dendritic staining (arrowhead). APP $\Delta$ Cterm is found in both axons and dendrites ( $\boldsymbol{D}$, mouse APP ${ }^{-1-} ; \boldsymbol{H}$, rat). Intracellular APP staining is shown for all constructs in both axons and dendrites $(\boldsymbol{I}-\boldsymbol{L}) . \boldsymbol{M}-\boldsymbol{P}$, Quantification of APP protein levels in axons versus dendrites is shown for expression in both rat neurons $(r)$ and mouse APP ${ }^{-/-}$neurons $(m)$. As described in the text, the axon- dendrite ratio shows the mean APP signal per micrometer in axons versus dendrites. At the cell surface $(\boldsymbol{M})$, APP-LDLR is highly polarized to the dendritic cell surface $\left({ }^{* *} p<0.01\right.$ vs APP). APP-NgCAM is found at levels approximately two times higher in axons than dendrites. APP $\Delta$ Cterm trended toward being less polarized than APP, but no statistical difference was found. There was no statistical difference between mouse APP ${ }^{-1-}$ neurons and rat neurons. Intracellular APP was less polarized for all constructs $(\boldsymbol{N})$, but APP-LDLR was still significantly polarized to the dendrites ${ }^{* *} p<0.01$ vs APP). The fraction of total APP signal in the axon versus dendrites is shown at the cell surface $(\boldsymbol{O})$ and intracellularly $\left(\boldsymbol{P} ; r\right.$, rat neurons; $m$, mouse APP ${ }^{-1-}$ neurons). More than $80 \%$ of APP-LDLR is found at the dendritic surface ${ }^{* *} p<0.01$ vs APP). Approximately, $80 \%$ of APP-NgCAM signal is at the axonal surface ( ${ }^{*} p<0.05$ vs APP). The difference between APP and APP-NgCAM is largely based on distal axonal staining not seen with APP. Surface APP $\Delta$ Cterm is nonpolarized ( ${ }^{*} p<0.05$ vs APP). Again, there was no significant difference between rat neurons and mouse APP ${ }^{-1-}$ neurons. At the intracellular level $(\boldsymbol{P})$, all constructs were less polarized, and there was no significant difference in axonal versus dendritic fractions among the different APP chimeras. Error bars indicate \pm SEM.
2001). Alternatively, we would propose that the membraneretained $\alpha$-CTF inhibits subsequent processing of this derivative by $\gamma$-secretase, as was elegantly demonstrated by Tian et al. (2010). Table 1 summarizes the identities of immunoprecipitated $A \beta$ related species and corresponding molecular weights that are present in the CM of primary rodent hippocampal neurons and hippocampal neurons expressing human APP-695.

\section{Targeting APP to axonal or dendritic compartments}

To determine whether $A \beta$ release occurs from axonal and/or dendritic compartments, we generated cDNA in which the cytoplasmic domain of APP was exchanged with the cytoplasmic domains from proteins targeted to axons or to dendrites in primary neurons. The LDLR contains a canonical basolateral sorting signal within its cytoplasmic domain that was shown to be sufficient for dendritic targeting within primary neuron cultures (Jareb and Banker, 1998; Silverman et al., 2005). Similarly, the NgCAM has a targeting signal located within its cytoplasmic domain shown to be sufficient for axonal targeting within primary neurons (Jareb and Banker, 1998; Yap et al., 2008). The APP chimeras that harbor the cytoplasmic domains of LDLR or NgCAM are shown in Figure $5 A, B$. In parallel, we generated cDNA encoding an APP construct with a deletion of the C-terminus (APP $\Delta$ Cterm), a domain that contains an endocytosis signals shown to important for $\mathrm{A} \beta$ production (Koo and Squazzo, 1994).

\section{APP-LDLR and APP-NgCAM are highly polarized to dendrites or axons, respectively}

We transfected constructs encoding APP-LDLR, APP-NgCAM, and APP $\triangle$ Cterm together with copGFP into primary rat neurons and primary neurons from $\mathrm{APP}$-deficient $\left(\mathrm{APP}^{-1-}\right)$ mice, as described above, to determine the polarized distribution of each chimera (Fig. 6). We failed to observe a significant difference in the polarized distribution of these chimeras between rat neurons versus mouse $\mathrm{APP}^{-1-}$ neurons (Fig. 6M,O). Surface staining using the human APP-specific mAb P2-1 revealed that APPLDLR is primarily localized to the dendritic domain (Fig. $6 B$, mouse; $F$, rat). At the cell surface, the axon-dendrite ratio for APP-LDLR is $0.25 \pm 0.04(p<0.01$ vs APP $)$ in rat neurons and $0.19 \pm 0.03\left(p<0.01\right.$ vs APP) in APP ${ }^{-/-}$mouse neurons (Fig. $6 M$ ). For APP-LDLR surface staining, total-surface staining for APP-LDLR is $16.6 \pm 1.8 \%$ on axonal membranes (vs $83.4 \%$ on dendritic membranes) in rat neurons ( $p<0.01 \mathrm{vs} \mathrm{APP)}$ and is $18.1 \pm 2.9 \%$ on the axonal membranes in $\mathrm{APP}^{-1-}$ neurons (vs $81.9 \%$ on dendritic membranes; $p$ value $<0.01$ vs APP; Fig. $6 O$ ). Conversely, APP-NgCAM was preferentially polarized to the axonal surface (Fig. $6 C$, mouse; $G$, rat), and surface staining showed an axon-dendrite ratio of $1.95 \pm 0.28$ in rat neurons and $1.89 \pm$ 0.34 in $\mathrm{APP}^{-1-}$ neurons (Fig. $6 M$ ). For APP-NgCAM surface staining, total-surface staining for $\mathrm{APP}-\mathrm{NgCAM}$ was $79.3 \pm 4.0 \%$ on the axonal surface versus $20.7 \%$ on dendritic membranes in rat neurons ( $p<0.05$ vs APP) and $83.8 \pm 3.0 \%$ on the axonal surface versus $16.2 \%$ on the dendritic membranes in $\mathrm{APP}^{-1-}$ neurons ( $p<0.05$ vs APP; Fig. 60 ). The difference in polarization indices between APP-695 and APP-NgCAM derives largely from APP-NgCAM staining in distal axons not seen with APP695, consistent with NgCAM distribution previously reported (Jareb and Banker, 1998). APP $\Delta$ Cterm shows a less polarized distribution (Fig. $6 D$, mouse; $H$, rat). At the cell surface, APP $\Delta$ Cterm has an axon-dendrite ratio of $1.28 \pm 0.22$ in rat neurons and $0.81 \pm 0.15$ in $\mathrm{APP}^{-1-}$ mouse neurons (Fig. 6M). For surface APP $\Delta$ Cterm, total-surface staining of APP $\Delta$ Cterm is $48.7 \pm 5.4 \%$ on the axonal membranes versus $51.3 \%$ on the 

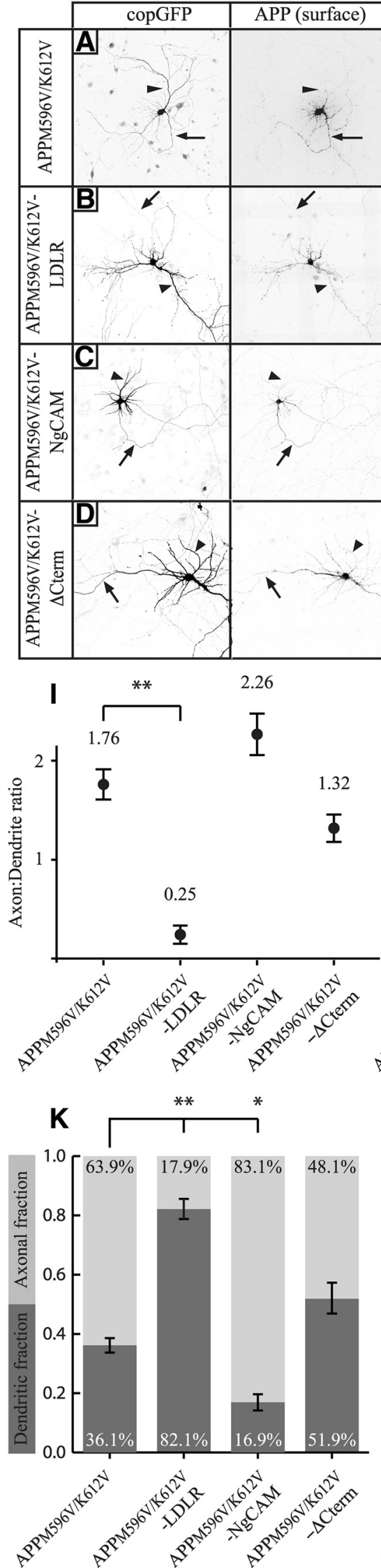
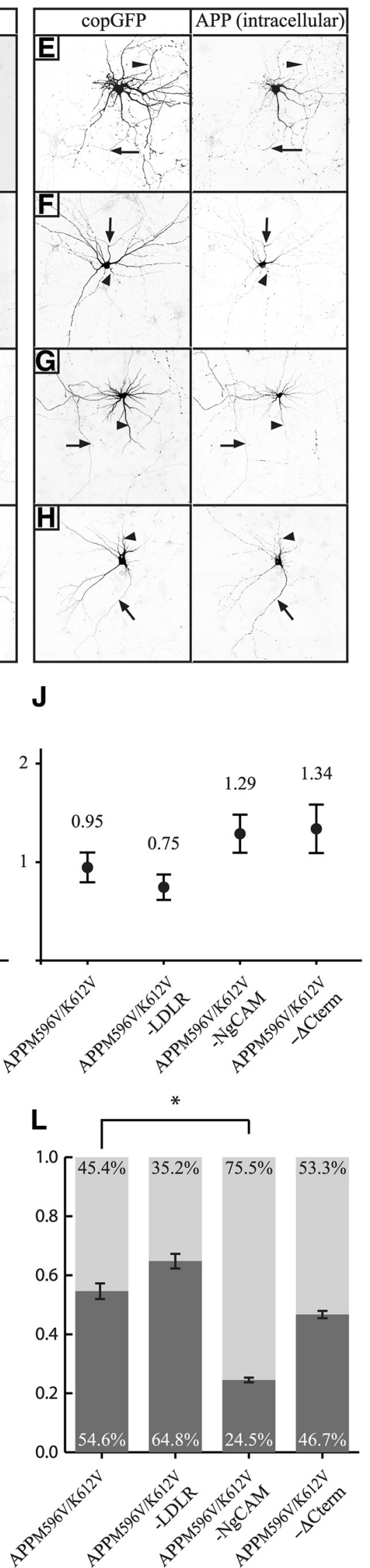

Figure 7. APPM596V/K612V chimeras in neurons. Neurons at 15-16 DIV cotransfected $24 \mathrm{~h}$ earlier with plasmids encoding copGFP and APPM596V/K612V, APPM596V/K612V-LDLR, APPM596V/K612V-NgCAM, or APPM596V/K612VDCterm. Surfacestaining for APP shows APP-LDLR $(\boldsymbol{B})$ is highly polarized to the dendrites (arrowhead), with little axonal staining (arrow).

dendritic membranes in rat neurons $(p<$ 0.05 vs APP) and $48.6 \pm 8.1 \%$ axonal (vs $51.4 \%$ dendritic) in $\mathrm{APP}^{-1-}$ neurons ( $p<0.05$ vs APP) (Fig. 6O). Therefore, the cytoplasmic domains of LDLR and NgCAM are sufficient to significantly alter the trafficking of APP.

To establish that the surface levels of APP chimeras are not confounded by differences in $\alpha$ - or $\beta$-secretase activities present in axonal or dendritic domains, we transfected neurons with constructs encoding APP-LDLR, APP-NgCAM, and $\mathrm{APP} \Delta$ Cterm harboring the M596V/ $\mathrm{K} 612 \mathrm{~V}$ mutations to preclude processing by $\alpha$ - and $\beta$-secretases (Fig. 7A-D). At the cell surface, APPM596V/K612V-LDLR is polarized to dendrites (Fig. $7 B$ ), with an axon-dendrite ratio of $0.25 \pm 0.05(p<$ 0.01 vs APPM596V/K612V; Fig. 7I). For surface APPM596V/K612V-LDLR, totalsurface staining of APPM596V/K612VLDLR is only $17.9 \pm 6.8 \%$ on axonal membranes $(82.1 \%$ on dendritic membranes; $p<0.01$ vs APPM596V/K612V; Fig. $7 \mathrm{~K})$. APPM596V/K612 $\mathrm{V}-\mathrm{NgCAM}$ is polarized to the axonal surface (Fig. $7 C$ ), with an axon-dendrite ratio of $2.26 \pm$ 0.28 (Fig. 7I). For surface APPM596V/ K612V-NgCAM, total-surface staining of APPM596V/K612V-NgCAM is $83.1 \pm$ $2.8 \%$ on the axonal membrane $(16.9 \%$ on the dendritic membrane; $p<0.05$ vs APPM596V/K612V;Fig.7K).APPM596V/ $\mathrm{K} 612 \mathrm{~V}-\Delta$ Cterm is less polarized (Fig. $7 D$ ),

APP-NgCAM $(\boldsymbol{C})$ is found at the axonal cell surface (arrow), with less dendritic staining (arrowhead). APP $\Delta$ Cterm (D) is found in both axons (arrow) and dendrites (arrowhead). Intracellular APP staining is shown for all APPM596V/K612V chimeras $(\boldsymbol{E}-\boldsymbol{H})$, demonstrating staining for all constructs in both axons (arrows) and dendrites (arrowheads). Quantification of APPM596V/K612V levels in the axon versus dendrites is shown in $(I-L)$. The axon-dendrite ratio $(I, J)$ measures the mean APP signal per micrometer in axons versus dendrites, whereas the axonal and dendritic fractions $(\boldsymbol{K}, \boldsymbol{L})$ measures the fraction of total APP signal found in the axons versus dendrites. At the cell surface $(\boldsymbol{I}, \boldsymbol{K})$, APPM596V/K612V-LDLR is highly polarized to the dendrites, with an axon-dendrite ratio of $0.25{ }^{* *} p<$ 0.01 vs APPM596V/K612V) and with $82.1 \%$ of APP signal found in the dendrites $\left({ }^{* *} p<0.01\right.$ vs APPM596V/K612V). APPM596V/K612V is enriched in the axons, with an axondendrite ratio of 2.26 and with $83.1 \%\left({ }^{*} p<0.05\right.$ vs APPM596V/K612V) of APP signal found in the axons. APPM596V/K612V $\Delta$ Cterm has an axon-dendrite ratio of 1.32, with $48.1 \%$ of APP signal found in the axons (no significant difference vs APPM596V/K612V). The quantification of intracellular staining $(\boldsymbol{J}, \boldsymbol{L})$ shows no significant difference in axon-dendrite ratios between the four APPM596V/K612V chimeras, but the sum of intracellular APPM596V/K612V$\mathrm{NgCAM}$ signal is $75.5 \%$ axonal $\left({ }^{*} p<0.05\right.$ vs APPM596V/ $\mathrm{K} 612 \mathrm{~V}$ ). This difference is due to staining of distal axons not seen with the other APPM596V/K612V chimeras. Error bars indicate \pm SEM. 

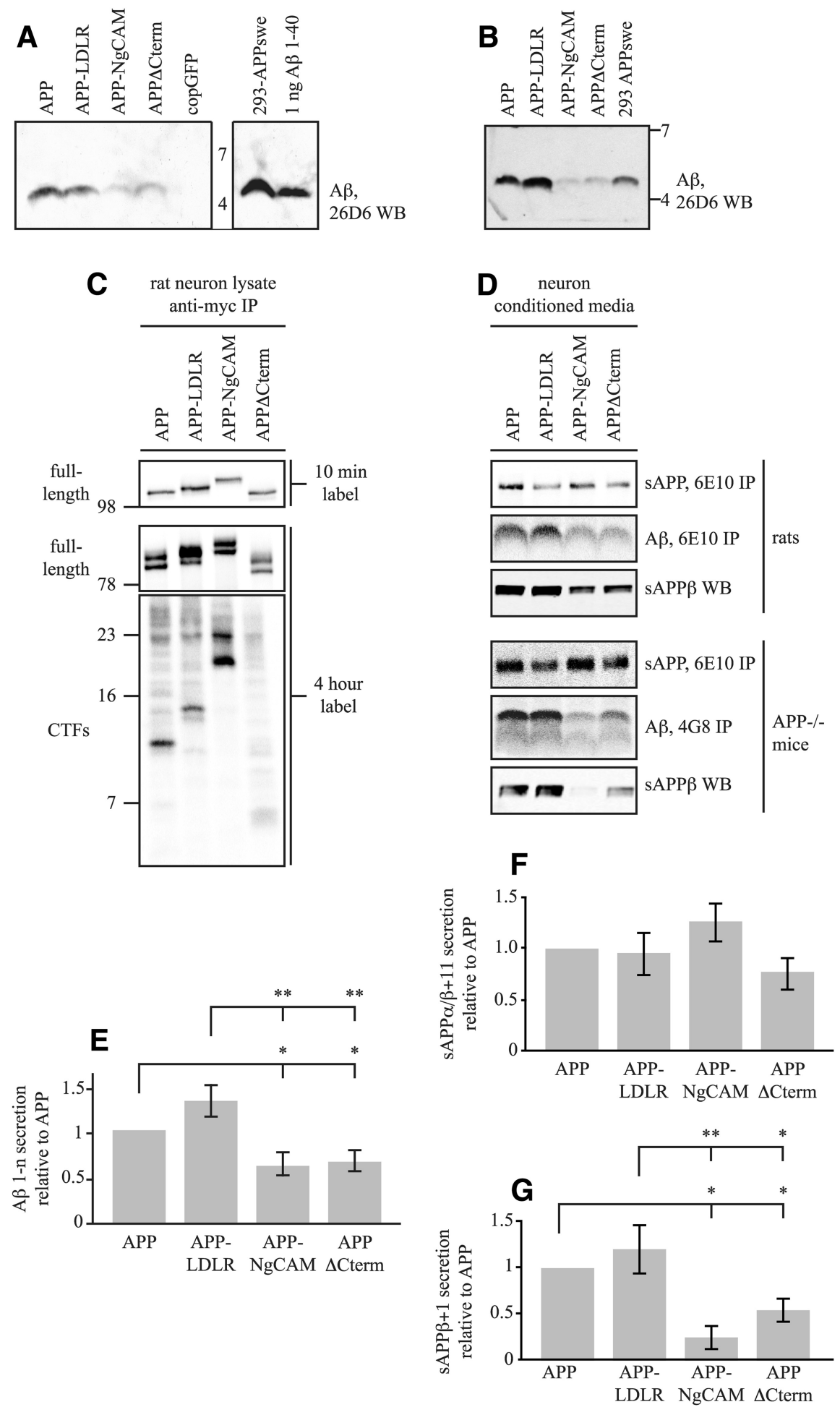

Figure 8. Quantification of $A \beta$ release using $S^{35}$-metabolic labeling. Neurons were transduced with lentiviruses encoding APP, APP-LDLR, APP-NgCAM, or APP $\Delta$ Cterm. At 15-16 DIV, A $\beta$ was immunoprecipitated using mAb 4G8 then subject to Western blotting with human-specific mAb $26 \mathrm{D} 6$ from the conditioned media of rat neurons $(\boldsymbol{A})$ or mouse $A P P^{-1-}$ neurons $(\boldsymbol{B})$. Less $A \beta$ is seen from APP-NgCAM or APP $\Delta$ Cterm compared with APP or APP-LDLR. C, At 15-16 DIV the neurons were labeled with $S^{35}$ methionine for either $10 \mathrm{~min}$ or $4 \mathrm{~h}$. APP was immunoprecipitated from the lysates using an anti-myc1 antibody. The APP full-length signal after the 10 min pulse was used to calculate the synthetic rate for each construct. At $4 \mathrm{~h}$, both immature and mature full-length APP can be seen, as well as APP CTFs. D, A $\beta$ was immunoprecipitated from the conditioned media from the $4 \mathrm{~h}$, continuously labeled neurons, using $4 \mathrm{G} 8$ (all $A \beta$ species) or the human-specific $6 \mathrm{E} 10$ antibody (A $\beta 1-n)$. SAPP $\alpha / \beta+11$ is also shown from the 6 E10 IPs. SAPP $\beta+1$ is shown by Western blot using the $\mathrm{APP} \beta$-specific antibody $192-$ WT. The same trend for all species is shown in both rat neurons and APP ${ }^{-1-}$ mouse neurons, similar to the results from IP/Western blot $(\boldsymbol{A}, \boldsymbol{B})$. More $A \beta$ is secreted from the dendritic APP-LDLR construct than from the axonal APP-NgCAM construct. Also, APP $\Delta$ Cterm shows less A $\beta$, as expected, due to the lack of an endocytosis signal. $\boldsymbol{E}$, Quantification of $A \beta 1-n$ from rat neuron conditioned media when normalized with an axon-dendrite ratio of $1.32 \pm 0.14$ (Fig. $7 I$ ) and with $48.1 \pm 10.9 \%$ of the total-surface staining of APPM596V/ K612V- $\Delta$ Cterm found at the axon surface ( $51.9 \%$ on the dendritic surface; Fig. $7 K)$. These surface polarization indices revealed similar results compared with the native APP chimeras that lack mutations at the $\alpha$ - and $\beta$-secretase sites. Thus, the polarization at the cell surface of the APP chimeras with intact $\alpha$ - and $\beta$-secretase cleavage sites likely reflects the distribution of full-length molecules and that shedding, were it to occur, has little impact on the observed outcomes.

Finally, to determine the intracellular levels of the chimeras with and without M596V/K612V mutations, we permeabilized fixed cells and performed IF staining using myc-I antibodies in 15-16 DIV neurons. In permeabilized neurons, APP chimeras with the native APP sequence are found in axons and dendrites, but less polarized than at the surface (Fig. 6I-L). Polarization indices are shown in Figure $6 N, P$. Intracellular APP-LDLR (Fig. $6 J$ ) is still polarized to the dendrites compared with intracellular APP-695, with an axondendrite ratio of $0.68 \pm 0.09(p<0.05 \mathrm{vs}$ APP; Fig. $6 N$ ). Total-intracellular staining of APP-LDLR found in axons versus in dendrites is 39.5 versus $60.5 \% \pm 3.4 \%$, respectively (Fig. 6P). Intracellular APPNgCAM staining (Fig. $6 K$ ) is also less polarized than surface APP-NgCAM staining, with an axon-dendrite ratio of $0.72 \pm 0.29$ (Fig. $6 N$ ). For intracellular APP-NgCAM, total-intracellular staining in axons versus intracellular staining in dendrites is 50.7 versus $49.3 \pm 9.0 \%$, respectively (Fig. $6 P$ ). Intracellular staining of APP $\Delta$ Cterm (Fig. $6 L$ ) shows an axondendrite ratio of $0.93 \pm 0.08$ (Fig. $6 N$ ), and total-intracellular staining of APP $\Delta$ Cterm in axons versus in dendrites is 46.7 versus $53.3 \pm 5.2 \%$, respectively (Fig. $6 P$ ).

The anti-mycl staining of permeabilized neurons expressing APPM596V/ $\mathrm{K} 612 \mathrm{~V}$ chimeras is shown in Figure $7 E-H$. Intracellular staining of APPM596V/ K612V-LDLR is still found predominantly in the dendrites (Fig. 7F) with an axon-dendrite ratio of $0.75 \pm 0.12$ (Fig. 7J). Total-intracellular staining of APPM596V/K612V-LDLR is only $35.2 \pm$

$\leftarrow$

to the 10 min synthetic rates of each construct. $\boldsymbol{F}$, Quantification of $\mathrm{SAPP} \alpha / \beta+11$ from rat neuron conditioned media when normalized to the 10 min synthetic rates of each construct. G, Quantification of SAPP $\beta$ from rat neuron conditioned media when normalized to the 10 min synthetic rates of each construct; ${ }^{*} p<0.05 ;{ }^{* *} p<0.01$. Error bars indicate \pm SEM. 

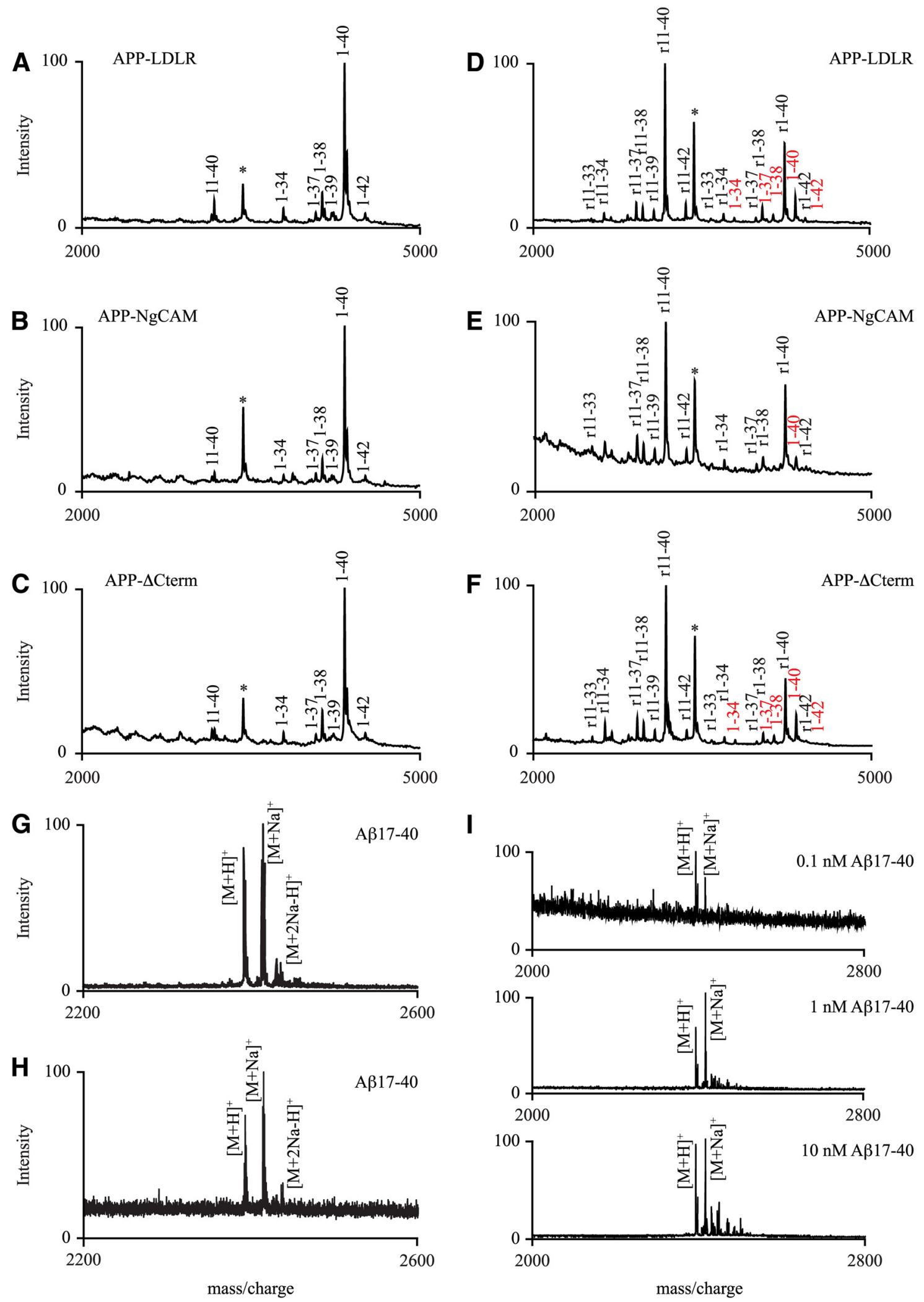

Figure 9. Soluble $A \beta$ peptides detected by mass spectrometry after $4 G 8 \mathrm{mAb}$ IP. Soluble $A \beta$ peptides derived from APP-chimera processing in mouse APP ${ }^{-1-}$ neurons $(A-C)$ or rat neurons $(\boldsymbol{D}-\boldsymbol{F})$ at 15-16 DIV. A $\beta$ was immunoprecipitated using 4G8, and then analyzed using MALDI-TOF mass spectrometry. Spectra from APP-LDLR $(\boldsymbol{A}), \operatorname{APP}-\mathrm{Ng} C A M(\boldsymbol{B})$, and APP $\Delta C$ term $(\boldsymbol{C})$ in APP ${ }^{-I-}$

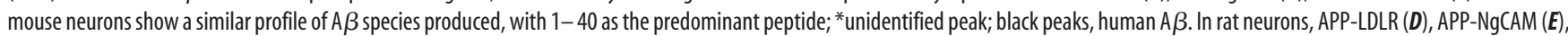
and $A P P \Delta C$ term also show a similar profile of $A \beta$ species produced, with 1-40 as the predominant peptide; *unidentified peak; black peaks, rat $A \beta(\mathrm{r} A \beta)$; red peaks, human $A \beta$. $A \beta 17-40$ is readily detectable by 4G8 IP followed by MALDI-TOF mass spectrometry (G-I). Purified human A $\beta 1-40(100 \mathrm{~nm}, \boldsymbol{G} ; 10 \mathrm{~nm}, \boldsymbol{H})$ was digested by trypsin, resulting in $A \beta 17-40(\boldsymbol{G}, \boldsymbol{H})$. Additionally, different concentrations of commercially available $A \beta 17-40$ were immunoprecipitated then subjected to mass spectrometry (I). $M, A \beta 17-40+H, N a$, or $2 \mathrm{NaH}$. 
Table 2. Soluble A $\beta$ species derived from APP chimera processing in APP ${ }^{-1-}$ neurons

\begin{tabular}{llll}
\hline $\begin{array}{l}\text { A } \beta \\
\text { species }\end{array}$ & Sequence & $\begin{array}{l}\mathrm{M}_{\mathrm{r}} \\
\text { (observed) }\end{array}$ & $\begin{array}{l}\mathrm{M}_{\mathrm{r}} \\
\text { (calculated) }\end{array}$ \\
\hline $1-42$ & DAEERHDSG YEVHHOKLVF FAEDVGSNKG AllGLMVGGV VIA & 4514.67 & 4514.10 \\
$1-40$ & DAEFRHDSG YEVHHOKLVF FAEDVGSNKG AllGLMVGGV V & 4330.87 & 4329.86 \\
$1-38$ & DAEERHDSG YEVHHOKLVF FAEDVGSNKG AllGLMVGG & 4132.46 & 4131.59 \\
$1-37$ & DAEFRHDSG YEVHHQKLVF FAEDVGSNKG AllGLMVG & 4075.75 & 4074.54 \\
$1-34$ & DAEFRHDSG YEVHHOKLVF FAEDVGSNKG AllGL & 3788.64 & 3787.16 \\
$11-40$ & EVHHQKLVF FAEDVGSNKG AllGLMVGGV V & 3152.58 & 3151.67 \\
$17-40^{*}$ & LVF FAEDVGSNKG AlIGLMVGGV V & 2393.46 & 2392.84 \\
\hline *17-40
\end{tabular}

*17-40 only seen in trace amounts in high APP-expressing cultures (not shown).

$4.9 \%$ in axons versus $64.8 \%$ in dendrites (Fig. $7 L$ ). Intracellular APPM596V/K612V-NgCAM (Fig. 7G) is polarized to the axon and has an axon-dendrite ratio of $1.29 \pm 0.25$ (Fig. $7 J$ ). For intracellular APPM596V/K612V-NgCAM, total-intracellular staining is $75.5 \pm 1.6 \%$ in the axons versus $24.5 \%$ in the dendrites $(p<0.05$ vs intracellular APPM596V/K612V). Intracellular APPM596V/K612V-NgCAM is more polarized than intracellular APP-NgCAM (without M596V/K612V; Fig. 6P), which indicates that the intracellular staining of APP-NgCAM may represent both full-length chimeras and the $\alpha$ - and/or $\beta$-secretasegenerated CTF derivatives (Fig. 7C). APPM596V/K612V$\Delta$ Cterm intracellular staining (Fig. $7 H$ ) is seen in both axons and dendrites and is similar to APP $\Delta$ Cterm intracellular staining, with an axon-dendrite ratio of $1.34 \pm 0.36$ (Fig. $7 J$ ). For intracellular APPM596V/K612V, total-intracellular staining is $53.3 \pm$ $2.5 \%$ in axons versus $46.7 \%$ in the dendrites (Fig. $7 L$ ).

\section{Elevated $A \beta$ production from dendritically targeted APP}

At 15-16 DIV, the conditioned media from primary neuron cultures transduced with lentiviruses encoding APP, APP-LDLR, APP-NgCAM, or APP $\Delta$ Cterm were subject to immunoprecipitation with mAb 4G8 antibody. The resulting immunoprecipitate was subject to Western blotting with the mAb 26D6 (anti-A $\beta$ $1-12$; Fig. $8 A$, rat neurons; $B$, mouse $\mathrm{APP}^{-1-}$ neurons). We observe that APP and APP-LDLR produced more A $\beta$ than APP$\mathrm{NgCAM}$ or APP $\Delta$ Cterm. Thus, when APP is targeted to dendrites, $A \beta$ secretion is elevated compared with APP targeted to axons. To quantify the levels of $\mathrm{A} \beta$ production among the different constructs, we metabolically labeled transduced rat neurons and $\mathrm{APP}^{-1-}$ mouse neurons (Fig. $8 C, D$ ) with ${ }^{35} \mathrm{~S}$ methionine. To determine the synthetic rate of full-length APP in transduced neurons, cells were pulse-labeled for $10 \mathrm{~min}$ and fulllength APP was immunoprecipitated with myc- 1 antiserum (Fig. $8 C)$. In parallel, we labeled transduced neurons for $4 \mathrm{~h}$ and performed IPs with the human-specific mAb 6E10 or mAb 4G8 (Fig. $8 D)$. The levels of secreted $A \beta$ were normalized to the $10 \mathrm{~min}$ synthetic rates of full-length APP (Fig. $8 E$ ). Neurons expressing APP-LDLR secrete $130.2 \pm 15 \%(p=0.07)$ more $1-n$ A $\beta$ species compared with neurons expressing human APP, whereas neurons expressing APP-NgCAM or APP $\Delta$ Cterm secrete $61.3 \pm$ $12 \%(p<0.01)$ and $64.4 \pm 11 \%(p<0.01)$ the levels of $1-n \mathrm{~A} \beta$ species compared with neurons expressing human APP, respectively. Very similar results are obtained when the APP chimeras are expressed in $\mathrm{APP}^{-1-}$ mouse neurons cultures (Fig. 8C). To assess whether dendritically targeted APP generates more $\mathrm{A} \beta$ because of alterations in $\alpha$ - or $\beta$-secretase processing, we examined the levels of sAPP $\alpha$ and sAPP $\beta$ in the conditioned media of transduced neurons (Fig. 8B). For sAPP $\alpha$, the CM from transduced neurons labeled for $4 \mathrm{~h}$ with ${ }^{35} \mathrm{~S}$-methionine were subject to immunoprecipitation with a human-specific antibody $6 \mathrm{E} 10$ that includes the first 15 aa of $\mathrm{A} \beta$ (Fig. $8 D$ ). The levels of secreted sAPP $\alpha$ were normalized to the $10 \mathrm{~min}$ synthetic rates of fulllength APP that were run in parallel. We observed no statistical differences in the levels of secreted sAPP $\alpha$ in conditioned medium from neurons expressing the four constructs, although there appeared to be a trend toward elevated levels in conditioned media of neurons expressing APP-NgCAM (Fig. $8 F$ ). The levels of sAPP $\beta$ from the conditioned media of 15-16 DIV neurons were analyzed by Western blot using the $\operatorname{sAPP} \beta$-specific polyclonal antibody 192-WT. In contrast to $\operatorname{sAPP} \alpha$, neurons expressing APP-NgCAM and APP $\Delta$ Cterm generated significantly less sAPP $\beta$ compared with APP $(40.9 \%, p<0.05$ and $62.1 \%$, $p<$ 0.05 , respectively; Fig. $8 G$ ). On the other hand, neurons expressing APP-LDLR lead to a slight $120.3 \%$ elevation in SAPP $\beta$ compared with neurons expressing APP, although this increase was not statistically significant (Fig. 8G). These latter analyses of secreted sAPP $\beta$ in the CM of transduced neurons are fully consistent with the Western blot (Fig. 8A,B), IP-MS studies (Fig. 7D) and radiolabeling/immunoprecipitation studies of secreted $\mathrm{A} \beta$ peptides (Fig. 8D).

\section{Soluble A $\boldsymbol{\beta}$ profiles from polarized APP constructs}

Although there is a clear difference in the levels of $1-n \mathrm{~A} \beta$ in the conditioned media of dendritically versus axonally targeted APP, we sought to identify all of the $\mathrm{A} \beta$ species that are produced from each construct. We performed 4G8 IPs followed by MALDI-TOF mass spectrometry to detect the $\mathrm{A} \beta$ species in $\mathrm{APP}{ }^{-1-}$ mouse neurons (Fig. 9A-C; Table 2) and in rat neurons (Fig. 9D-F), as shown above for APP (Fig. 4). We observed abundant levels of $\mathrm{A} \beta 1-40$ and low levels of $\mathrm{A} \beta 11-40$, but again we failed to detect the presence of $A \beta 17-40 / 42$ in the $C M$ of transduced neurons. To establish that we could detect $A \beta 17-40$ by 4 G 8 IP followed by MALDI-TOF mass spectrometry, we treated 10 or 100 nmole of purified human $A \beta 1-40$ with 22 ng of trypsin to cleave the peptide at the K-L scissile site (Fig. 4A) and subjected the reaction mixtures to MALDI-TOF spectrometry (Fig. 9G, $H$, respectively). We clearly detected $A \beta 17-40$ in both spectra. Finally, to examine whether we had the sensitivity to detect $A \beta 17-40$, we subjected commercially available $\mathrm{A} \beta 17-40$ to $4 \mathrm{G} 8$ IPs and MALD-TOF mass spectrometry and showed that as little as 0.1 nм A $\beta 17-40$ present in $1 \mathrm{ml}$ is readily detectable (Fig. $9 I$ ). Hence, we are certain that if this peptide were present in the CM of transduced neurons, we would have detected it. Finally, considering the possibility that the 4G8 epitope may have been masked in some way, we confirmed these findings by repeating the IP/ MALDI-TOF studies using antibody mAb 2G3, specific for the C-terminus of $\mathrm{A} \beta \mathrm{x}-40$ peptides. These studies also failed to identify $\mathrm{A} \beta 17-40$ in the CM of transduced neurons (Fig. 10).

\section{Discussion}

Although APP-695 is expressed predominantly by neurons within the rodent brain, the processing and trafficking of APP in neuronal cells is poorly understood. In this regard, presenilin, the catalytic component of the $\gamma$-secretase complex, is distributed within both axons and the somatodendritic domain, but at very low levels on the cell surface (Cook et al., 1996; Kovacs et al., 1996; Busciglio et al., 1997). Similarly, BACE is also distributed within both axons and dendrites in vitro, but is highly polarized to axonal domains in vivo (Capell, 2002; Buggia-Prévot et al., 2013). ADAM10, the presumptive constitutive neuronal $\alpha$-secretase, is found in dendrites at the postsynaptic density (Marcello et al., 2007) and within axons (Szodorai et al., 2009). A series of earlier efforts has revealed that APP is located in both axonal and den- 
A

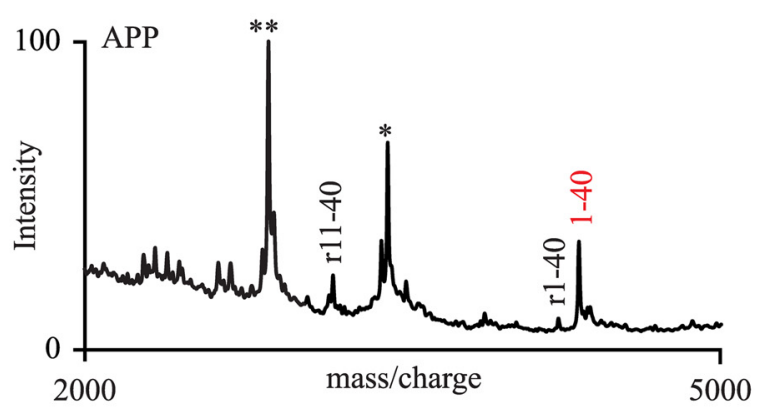

B

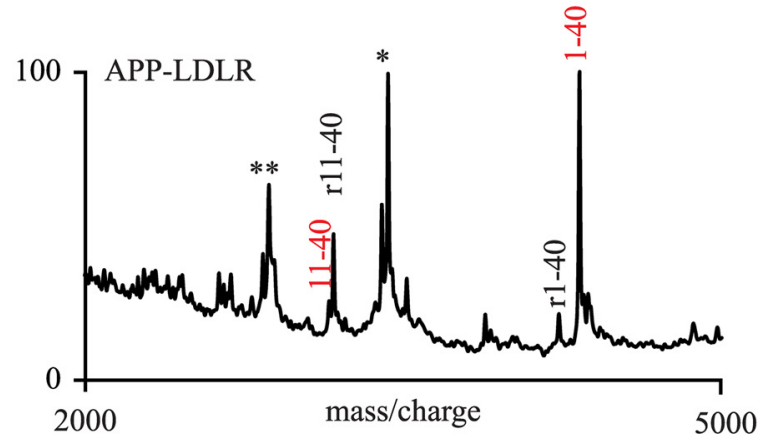

C

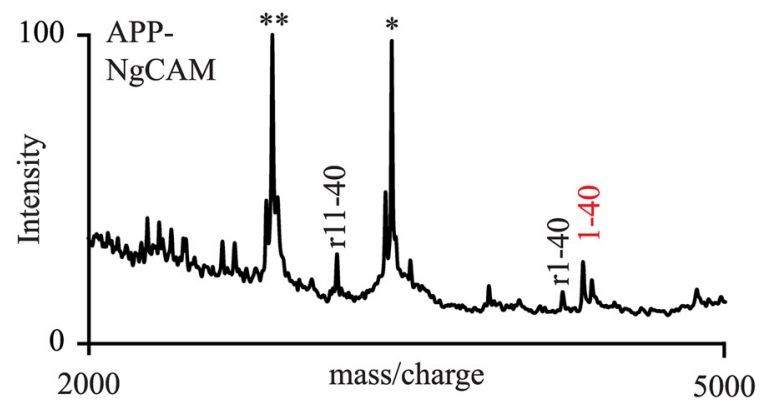

D

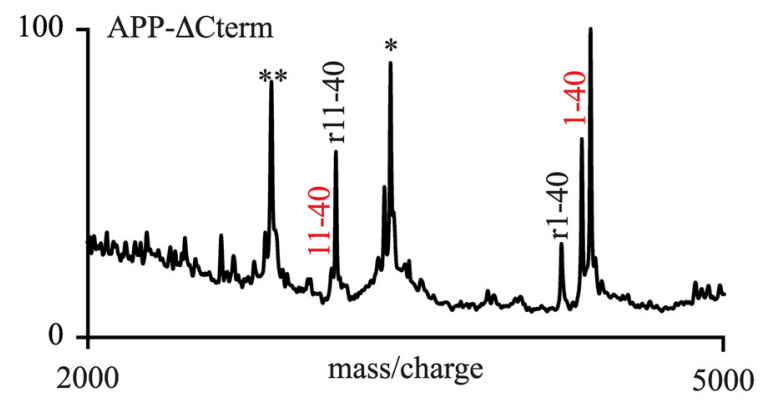

E

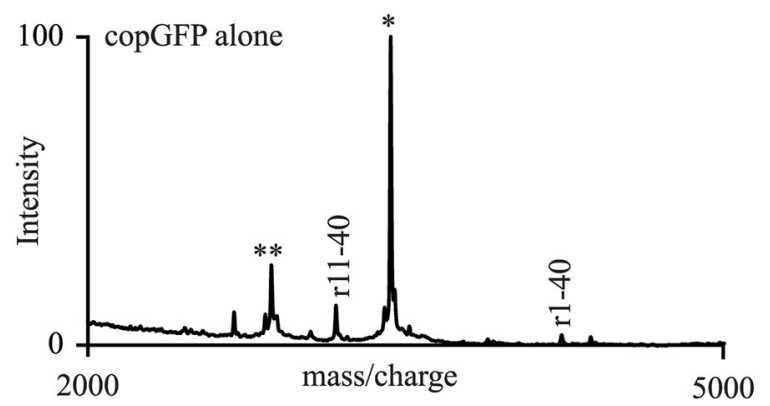

Figure 10. Soluble $A \beta$ peptides derived from APP-chimera processing in rat neurons at $15-16$ DIV detected by 2 G3 from conditioned media. $A \beta$ was immunoprecipitated using $2 G 3$, then analyzed using MALDI-TOF mass spectrometry. Spectra from APP $(\boldsymbol{A})$, APP-LDLR $(\boldsymbol{B})$, APP$\mathrm{NgCAM}(\boldsymbol{C}), \operatorname{APP} \Delta$ Cterm $(\boldsymbol{D})$, and copGFP alone $(\boldsymbol{E})$ in rat neurons show a similar profile of $A \beta$ species produced, with $1-40$ as the predominant exogenous peptide; ${ }^{*}$ unidentified peak; ${ }^{*}$ internal standard; red peaks, human $\mathrm{A} \beta$; black peaks, rat $\mathrm{A} \beta(\mathrm{rA} \beta)$. dritic compartments (Ferreira et al., 1993; Yamazaki et al., 1995; Wei et al., 2010) and that APP undergoes fast axonal transport (Koo et al., 1990; Sisodia et al., 1993; Buxbaum et al., 1998; Lyckman et al., 1998; Kaether et al., 2000; Szodorai et al., 2009). Importantly, synaptic activity increases $\mathrm{A} \beta$ release both in vitro and in vivo (Lazarov et al., 2002; Kamenetz et al., 2003; Cirrito et al., 2005). Indeed, studies by Wei et al. (2010) revealed that $A \beta$ peptides released from presynaptic or postsynaptic compartments can exert neurotoxic effects on spines and synaptic function. In these studies, APP was expressed either in CA1 pyramidal neurons to assess the effects of postsynaptically released $A \beta$ on dendritic spines of uninfected CA1 cells or expressed in CA3 projection neurons to assess the impact of presynaptically released $A \beta$ on dendritic spines of CA1 neurons. Although elegant in design, this experimental paradigm fails to provide information regarding the levels of APP expression in transduced cells or the identity of $A \beta$ peptides released from presynaptic or postsynaptic compartments. We have examined these issues by directing expression of human APP-695 chimeras selectively to axonal or dendritic compartments and we now offer several important insights. First, we demonstrate that chimeras of the APP ectodomain and APP transmembrane segments fused to the cytoplasmic domains of either NgCAM or LDLR are targeted to axons and dendrites, respectively, and in a manner that faithfully recapitulate the distribution of full-length NgCAM (Jareb and Banker, 1998; Yap et al., 2008) or LDLR (Jareb and Banker, 1998; Silverman et al., 2005), respectively. A confounding issue is that although numerous studies have revealed the presence of native APP in a variety of intraneuronal compartments, these studies used antibodies that cannot distinguish between full-length APP or APP derivatives (sAPP or APP-CTFs; Ferreira et al., 1993; Yamazaki et al., 1995; Muresan et al., 2009). To overcome this uncertainty, we generated cDNA encoding APP-NgCAM or APP-LDLR chimeras in which the $\alpha$ - and $\beta$-secretase cleavage sites were mutagenized. We now report that the steady-state distribution of the $\alpha$ - and $\beta$-secretase cleavage mutant (M596V/ $\mathrm{K} 612 \mathrm{~V}$ ) is indistinguishable from the native APP-695. For example, whereas native APP is detected at higher levels on the axonal surface compared with the dendritic surface, APP-specific immunoreactivity is distributed in a nonpolarized manner in permeabilized cells. This result is replicated by analysis of the APP-M596V/K612V mutant, thus indicating that the bulk of APP detected on the cell surface or in permeabilized cells is likely to represent full-length APP. It is important to note that our studies examine the distribution of APP at steady-state, and hence we cannot draw conclusions regarding the trafficking itinerary of the chimeras. In this regard, studies have shown that APP is internalized from axonal compartments and transcytosed to somatodendritic domains (Simons et al., 1995; Yamazaki et al., 1995). Future studies using live-cell imaging approaches will be required to settle these important issues.

Second, we have used IP-MALDI-TOF mass spectrometry to identify the entire spectrum of $A \beta$ species secreted from either primary rat hippocampal neurons or mouse $\mathrm{APP}^{-/-}$neurons transduced with lentiviruses harboring cDNA encoding human APP-695, or human APP-695 harboring the cytoplasmic domains of NgCAM or LDLR. In every case, the principal $A \beta$ related species is $A \beta 1-40$. Interestingly, $A \beta 17-40$, termed "p3," the expected product of $\alpha$-secretase and $\gamma$-secretase processing of $\alpha$-CTF, is nearly undetectable despite the fact that significant levels of sAPP $\alpha$ and $\alpha$-CTF are detectable in the conditioned media and cell lysates, respectively. This is unlikely to be a technical issue as we have demonstrated that the $17-40$ peptide is 
readily detected by IP-MALDI-TOF mass spectrometry (Fig. 9G-I), and identical results were obtained using independent antibodies to different $\mathrm{A} \beta$ epitopes for the immunoprecipitation. It is also conceivable that proteases in the CM of primary neurons actively degrade secreted $\mathrm{p} 3$ peptides, thus precluding detection. We would favor the model that the reason for our inability to detect $\mathrm{A} \beta 17-40$ is because $\alpha$-CTF is inefficiently processed by neurons to generate $\mathrm{A} \beta 17-40$. This conclusion derives from the finding that $\alpha$-CTF inhibits subsequent processing of this derivative by $\gamma$-secretase (Tian et al., 2010).

Another noteworthy result from our dataset is the significant difference in secreted $A \beta$ profiles from endogenous rat APP versus from transduced rat neurons expressing human APP. Human APP is processed primarily to A $\beta 1-40$, whereas rat APP is processed primarily to $A \beta 11-40$. This result is in agreement with earlier studies showing that rodent BACE1 cleavage of human APP at the +11 site is inefficient and is likely due to amino acid differences between human and rodent APP that are in proximity to the +11 site (Cai et al., 2001). In this regard, experimental evidence obtained through mutagenesis studies revealed that BACE1 cleaves rodent at the +11 site more efficiently due to the presence of a glycine residue at position $\mathrm{P} 6$ relative to the scissile phenylalanine-glutamate bond (Fig. 4A,F,E; Qahwash et al., 2004).

Finally, we report that although $A \beta$ is released from neurons in which APP is targeted to either dendritic or axonal compartments, there is a significant difference in the levels of $\mathrm{A} \beta$ released from the two compartments. These differences are apparent both by Western blot assays, ${ }^{35} \mathrm{~S}$-metabolic labeling, and semiquantitative IP-MALDI/TOF analyses. Our studies reveal that dendritically targeted APP leads to elevated $\mathrm{A} \beta$ secretion compared with axonally targeted APP, a result that is consistent with our finding that lower levels of sAPP $\beta$ are released from neurons expressing the axonally targeted APP-NgCAM chimera. It is presently unclear whether these apparent differences in levels of secreted $A \beta$ species derived from axon- versus dendrite-targeted APP reflects the relative steady-state distribution and/or activity of BACE1. In this regard, it is well established that BACE1 is catalytically active in endosomes, and we would envision that APP may encounter $\mathrm{BACE} 1$ to a greater degree in recycling endosomes that are more prominent in somatodendritic compartments compared with axons. Further studies to examine the itinerary of APP and BACE1 using dynamic imaging strategies and neo-epitopespecific antibodies in situ will be required to clarify these critical aspects of APP processing in neurons.

\section{References}

Buggia-Prévot V, Fernandez CG, Udayar V, Vetrivel KS, Elie A, Roseman J, Sasse VA, Lefkow M, Meckler X, Bhattacharyya S, George M, Kar S, Bindokas VP, Parent AT, Rajendran L, Band H, Vassar R, Thinakaran G (2013) A function for EHD family proteins in unidirectional retrograde dendritic transport of BACE1 and Alzheimer's disease $\mathrm{A} \beta$ production. Cell Rep 5:1552-1563. CrossRef Medline

Busciglio J, Hartmann H, Lorenzo A, Wong C, Baumann K, Sommer B, Staufenbiel M, Yankner BA (1997) Neuronal localization of presenilin-1 and association with amyloid plaques and neurofibrillary tangles in Alzheimer's disease. J Neurosci 17:5101-5107. Medline

Buxbaum JD, Thinakaran G, Koliatsos V, O'Callahan J, Slunt HH, Price DL, Sisodia SS (1998) Alzheimer amyloid protein precursor in the rat hippocampus: transport and processing through the perforant path. J Neurosci 18:9629-9637. Medline

Cai H, Wang Y, McCarthy D, Wen H, Borchelt DR, Price DL, Wong PC (2001) BACE1 is the major $\beta$-secretase for generation of $A \beta$ peptides by neurons. Nat Neurosci 4:233-234. CrossRef Medline

Capell A, Meyn L, Fluhrer R, Teplow DB, Walter J, Haass C (2002) Apical sorting of beta-secretase limits amyloid beta-peptide production. J Biol Chem 277:5637-5643. CrossRef Medline

Cirrito JR, Yamada KA, Finn MB, Sloviter RS, Bales KR, May PC, Schoepp DD, Paul SM, Mennerick S, Holtzman DM (2005) Synaptic activity regulates interstitial fluid amyloid-beta levels in vivo. Neuron 48:913-922. CrossRef Medline

Citron M, Oltersdorf T, Haass C, McConlogue L, Hung AY, Seubert P, VigoPelfrey C, Lieberburg I, Selkoe DJ (1992) Mutation of the beta-amyloid precursor protein in familial Alzheimer's disease increases beta-protein production. Nature 360:672-674. CrossRef Medline

Cook DG, Sung JC, Golde TE, Felsenstein KM, Wojczyk BS, Tanzi RE, Trojanowski JQ, Lee VM, Doms RW (1996) Expression and analysis of presenilin 1 in a human neuronal system: localization in cell bodies and dendrites. Proc Natl Acad Sci U S A 93:9223-9228. CrossRef Medline

Das SS, Banker GA (2006) The role of protein interaction motifs in regulating the polarity and clustering of the metabotropic glutamate receptor mGluRla. J Neurosci 26:8115-8125. CrossRef Medline

Ferreira A, Caceres A, Kosik KS (1993) Intraneuronal compartments of the amyloid precursor protein. J Neurosci 13:3112-3123. Medline

Haass C, Hung AY, Schlossmacher MG, Teplow DB, Selkoe DJ (1993) $\beta$-Amyloid peptide and a $3-\mathrm{kDa}$ fragment are derived by distinct cellular mechanisms. J Biol Chem 268:3021-3024. Medline

Haass C, Kaether C, Thinakaran G, Sisodia S (2012) Trafficking and proteolytic processing of APP. Cold Spring Harb Perspect Med 2:a006270. CrossRef Medline

Hung AY, Koo EH, Haass C, Selkoe DJ (1992) Increased expression of betaamyloid precursor protein during neuronal differentiation is not accompanied by secretory cleavage. Proc Natl Acad Sci U S A 89:9439-9443. CrossRef Medline

Jareb M, Banker G (1998) The polarized sorting of membrane proteins expressed in cultured hippocampal neurons using viral vectors. Neuron 20:855-867. CrossRef Medline

Kaech S, Banker G (2006) Culturing hippocampal neurons. Nat Protoc 1:2406-2415. CrossRef Medline

Kaether C, Skehel P, Dotti CG (2000) Axonal membrane proteins are transported in distinct carriers: a two-color video microscopy study in cultured hippocampal neurons. Mol Biol Cell 11:1213-1224. CrossRef Medline

Kamenetz F, Tomita T, Hsieh H, Seabrook G, Borchelt D, Iwatsubo T, Sisodia S, Malinow R (2003) APP processing and synaptic function. Neuron 37:925-937. CrossRef Medline

Kinoshita A, Fukumoto H, Shah T, Whelan CM, Irizarry MC, Hyman BT (2003) Demonstration by FRET of BACE interaction with the amyloid precursor protein at the cell surface and in early endosomes. J Cell Sci 116:3339-3346. CrossRef Medline

Koo EH, Squazzo SL (1994) Evidence that production and release of amyloid beta-protein involves the endocytic pathway. J Biol Chem 269: 17386-17389. Medline

Koo EH, Sisodia SS, Archer DR, Martin LJ, Weidemann A, Beyreuther K, Fischer P, Masters CL, Price DL (1990) Precursor of amyloid protein in Alzheimer disease undergoes fast anterograde axonal transport. Proc Nat Acad Sci U S A 87:1561-1565. CrossRef Medline

Kovacs DM, Fausett HJ, Page KJ, Kim TW, Moir RD, Merriam DE, Hollister RD, Hallmark OG, Mancini R, Felsenstein KM, Hyman BT, Tanzi RE, Wasco W (1996) Alzheimer-associated presenilins 1 and 2: neuronal expression in brain and localization to intracellular membranes in mammalian cells. Nat Med 2:224-229. CrossRef Medline

Lazarov O, Lee M, Peterson DA, Sisodia SS (2002) Evidence that synaptically released $\beta$-amyloid accumulates as extracellular deposits in the hippocampus of transgenic mice. J Neurosci 22:9785-9793. Medline

Lo AC, Haass C, Wagner SL, Teplow DB, Sisodia SS (1994) Metabolism of the "Swedish" amyloid precursor protein variant in Madin-Darby canine kidney cells. J Biol Chem 269:30966-30973. Medline

Lyckman AW, Confaloni AM, Thinakaran G, Sisodia SS, Moya KL (1998) Post-translational processing and turnover kinetics of presynaptically targeted amyloid precursor superfamily proteins in the central nervous system. J Biol Chem 273:11100-11106. CrossRef Medline

Marcello E, Gardoni F, Mauceri D, Romorini S, Jeromin A, Epis R, Borroni B, Cattabeni F, Sala C, Padovani A, Di Luca M (2007) Synapse-associated protein-97 mediates $\alpha$-secretase ADAM10 trafficking and promotes its activity. J Neurosci 27:1682-1691. CrossRef Medline

Muresan V, Varvel NH, Lamb BT, Muresan Z (2009) The cleavage products of amyloid-beta precursor protein are sorted to distinct carrier vesicles 
that are independently transported within neurites. J Neurosci 29:35653578. CrossRef Medline

Price DL, Sisodia SS (1998) Mutant genes in familial Alzheimer's disease and transgenic models. Annu Rev Neurosci 21:479-505. CrossRef Medline

Qahwash I, He W, Tomasselli A, Kletzien RF, Yan R (2004) Processing amyloid precursor protein at the beta-site requires proper orientation to be accessed by BACE1. J Biol Chem 279:39010-39016. CrossRef Medline

Silverman MA, Peck R, Glover G, He C, Carlin C, Banker G (2005) Motifs that mediate dendritic targeting in hippocampal neurons: a comparison with basolateral targeting signals. Mol Cell Neurosci 29:173-180. CrossRef Medline

Simons M, Ikonen E, Tienari PJ, Cid-Arregui A, Mönning U, Beyreuther K, Dotti CG (1995) Intracellular routing of human amyloid protein precursor: axonal delivery followed by transport to the dendrites. J Neurosci Res 41:121-128. CrossRef Medline

Sisodia SS (1992) Beta-amyloid precursor protein cleavage by a membranebound protease. Proc Natl Acad Sci U S A 89:6075-6079. CrossRef Medline

Sisodia SS, Koo EH, Hoffman PN, Perry G, Price DL (1993) Identification and transport of full-length amyloid precursor proteins in rat peripheral nervous system. J Neurosci 13:3136-3142. Medline

Szodorai A, Kuan YH, Hunzelmann S, Engel U, Sakane A, Sasaki T, Takai Y, Kirsch J, Müller U, Beyreuther K, Brady S, Morfini G, Kins S (2009) APP anterograde transport requires Rab3A GTPase activity for assembly of the transport vesicle. J Neurosci 29:14534-14544. CrossRef Medline

Tian Y, Crump CJ, Li YM (2010) Dual role of $\alpha$-secretase cleavage in the regulation of $\gamma$-secretase activity for amyloid production. J Biol Chem 285:32549-32556. CrossRef Medline

Van Nostrand WE, Wagner SL, Suzuki M, Choi BH, Farrow JS, Geddes JW, Cotman CW, Cunningham DD (1989) Protease nexin-II, a potent antichymotrypsin, shows identity to amyloid beta-protein precursor. Nature 341:546-549. CrossRef Medline

Wei W, Nguyen LN, Kessels HW, Hagiwara H, Sisodia S, Malinow R (2010) Amyloid beta from axons and dendrites reduces local spine number and plasticity. Nat Neurosci 13:190-196. CrossRef Medline

Yamazaki T, Selkoe DJ, Koo EH (1995) Trafficking of cell surface betaamyloid precursor protein: retrograde and transcytotic transport in cultured neurons. J Cell Biol 129:431-442. CrossRef Medline

Yap CC, Nokes RL, Wisco D, Anderson E, Fölsch H, Winckler B (2008) Pathway selection to the axon depends on multiple targeting signals in NgCAM. J Cell Sci 121:1514-1525. CrossRef Medline

Zheng H, Jiang M, Trumbauer ME, Sirinathsinghji DJ, Hopkins R, Smith DW, Heavens RP, Dawson GR, Boyce S, Conner MW, Stevens KA, Slunt HH, Sisoda SS, Chen HY, Van der Ploeg LH (1995) $\beta$-Amyloid precursor protein-deficient mice show reactive gliosis and decreased locomotor activity. Cell 81:525-531. CrossRef Medline 